Alma Mater Studiorum - Università di Bologna DEPARTMENT OF ECONOMICS

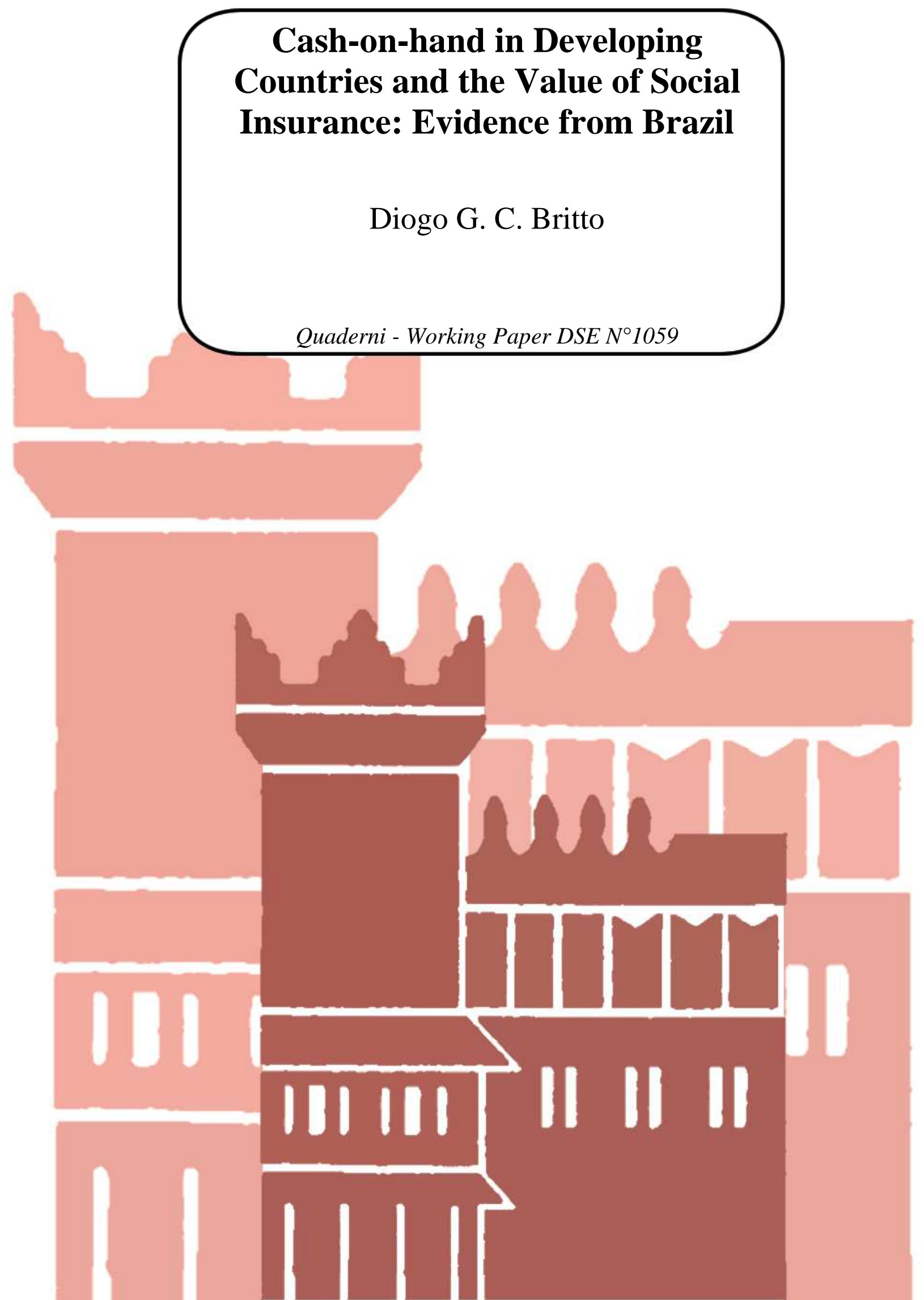




\title{
Cash-on-hand in Developing Countries and the Value of Social Insurance: Evidence from Brazil
}

\author{
Diogo G. C. Britto*
}

November 20, 2015

\begin{abstract}
This paper first exploits a "bonus" policy providing low-income workers with cash grants in Brazil to study the effect of liquidity provision on unemployment outcomes. Based on a RD Design, I find that granting unemployed workers with a bonus equal to half of their previous monthly earnings decreases the probability of exiting unemployment within 8 weeks by around $0.65 \%$. Second, by exploiting the UI potential duration schedule, I find that granting workers with an extra month of unemployment benefits decreases the same outcome by 1.9\%. Then, theoretical results from Landais (2014) are used to combine these estimates and disentangle liquidity and moral hazard effects of UI. Based on these, I estimate the liquidity-to-moral hazard ratio in Brazil to be as large as $98 \%$, similarly to values previously found in the US. It suggests that, contrary to common belief, providing UI in developing countries with large informal labor markets may yield substantial welfare gains.
\end{abstract}

JEL classification: I38, J65.

Keywords: Unemployment Insurance, Unemployment Duration, Liquidity-to-Moral Hazard Ratio, Informal Labor Market.

*E-mail: diogo.gerhardcastro5@unibo.it ; I thank Giulio Zanella, Renata Bottazzi, Tobias Hlobil, and seminar participants at the Department of Economics/Bologna 


\section{Introduction}

Learning about the size of liquidity effects on the behavior of unemployed workers is fundamental for evaluating how large are the welfare benefits from unemployment insurance (UI). There is however rather scarce empirical evidence on this effect. This paper takes advantage of a "bonus policy" in Brazil which grants low-income workers with a cash bonus. By applying a regression discontinuity design, I exploit an eligibility condition for the cash grant to estimate the effects of liquidity provision on unemployment outcomes in a clean identification environment. However, a main statistic of interest for evaluating the welfare gains from UI is the so liquidity-to-moral hazard ratio, as shown by Chetty (2008). Therefore, I perform a further empirical analysis and propose a strategy to fully identify this ratio. I apply again a second regression discontinuity design to assess the effect of UI potential duration on the same unemployment outcomes. Such response is a composition of liquidity and moral hazard effects, as shown by Chetty (2008). Then, I take advantage of theoretical results by Landais (2014) to put together the effects of the cash bonus policy (the liquidity effetcs) and the effects of extended UI potential duration (liquidity plus moral hazard effect) in order to isolate the moral hazard effect. In such a way, I am able to estimate the liquidity-to-moral hazard ratio in the context of Brazil.

There exists a rather large body of empirical evidence assessing how unemployment benefits affect unemployment outcomes. One established finding is that workers take longer periods to find a new job as UI increases, either in terms of levels or potential duration. However, one key issue for policy is evaluating to what extent such benefits achieve its main goal: avoiding that jobless workers face drops in consumption which are too large. In other words, the key efficiency gain from providing temporary income assistance to the unemployed is allowing workers to better smooth consumption when in between jobs. Nevertheless, it is an empirical challenge to assess how UI benefits affect consumption because data on the later typically comes from surveys and is very imprecise. Chetty (2008) proposes a solution to this problem and shows that it is possible, and equivalent, to evaluate welfare gains from UI by looking at how unemployment duration reacts to changes in liquidity vis-a-vis to changes in unemployment benefits: the so-called liquidity-to-moral hazard ratio. He notices that unemployed workers take longer to find a new job when UI increases because of two reasons: (i) higher benefit level makes workers less liquidity constrained, so that they do not need to search "too fast" for a new job: the liquidity effect; and (ii) higher benefit level increases moral hazard because once workers find a new job they are no longer entitled to receive benefits: the moral hazard effect. The key theoretical finding from his work is that while the second effect is rather detrimental to welfare, the first effect is non-detrimental and is actually an alternative measure to the gains from consumption smoothing. Welfare gains from UI can then be evaluated by estimating the ratio between these two effects. In this framework, optimal UI policy consists therefore of finding the right balance between providing liquidity to constrained job seekers and avoiding moral hazard effects which are too large. 
There is however scarce credible evidence in the literature of how large the liquidity-to-moral hazard ratio really is. In this work, I first take advantage of a policy in Brazil which provides an unconditional "bonus income" to low income workers to estimate the liquidity effect: how unemployed workers react to a liquidity provision which yields no moral hazard. Unlike unemployment benefits, this policy does not create moral hazard because the unemployed do not lose this bonus in case they find a new job. Second, I explore the schedule of UI potential duration in Brazil to assess how potential duration affects the duration of employment. Such an effect is a composition of a liquidity and a moral hazard component. Finally, I use these two estimates to disentangle the moral hazard component from the liquidity effect by using a theoretical result due to Landais (2014). In such a way, it is possible to estimate the liquidityto-moral hazard ratio, which I find to be close to 0.98 in Brazil, an estimate which is similarly to the one previously found by Landais (2014) using data from the US.

In order to estimate the liquidity effect, I exploit a policy in Brazil (Abono Salarial) which yearly grants low-income workers with a "bonus" payment equal to one monthly minimum wage. To be eligible for the bonus, beneficiaries average earnings in the previous year must not have exceed two times the minimum wage at that time. The grant then is unconditional to employment status in the payment year. I use this condition to estimate how the unemployed react to receiving this bonus at the beginning of their spell by applying a regression discontinuity design. I find that granting unemployed workers around this eligibility threshold with one monthly minimum wage decreases the probability of finding a new job in the first eight weeks of unemployment by $0.65 \%$. This estimates the liquidity effect.

To assess the moral hazard effect, I first exploit the Brazilian UI schedule of potential duration. It grants displaced workers who have reached 24 months of tenure with an extra month of potential unemployment benefits. I use again a regression discontinuity to assess how workers around this threshold react to this extension and find that it decreases their probability of finding a new job in the first eight weeks of unemployment by $1.9 \% .^{1}$ This estimate embodies both a liquidity and a moral hazard effect.

From the two empirical analyses briefly described in the two previous paragraphs, I draw estimates of the liquidity effect (from the bonus policy) and of the full effect of UI (from the UI schedule assigning potential duration) which is a sum of liquidity and moral hazard. From these two estimates it is possible to recover the liquidity-to-moral hazard ratio. It is however not immediate, because first it is necessary to isolate the moral hazard effect from the second estimate described in the previous paragraph above. It is also important to notice that the bonus policy provides an increase in liquidity at the beginning of the unemployment spell, while an increase in potential duration works as an increase in benefit level at the end of the UI covered unemployment duration. Thus, in order to combine these results and isolate the moral hazard component, I take advantage of a theoretical result from Landais (2014) which links

\footnotetext{
${ }^{1}$ This RDD strategy is the same used by Gerard and Gonzaga (2013) who are interested in a related but different outcome related to unemployment outcomes.
} 
UI, liquidity and moral hazard effects at different points in time. Then, it is possible to estimate the moral hazard component and, finally, the liquidity-to-moral hazard ratio.

The main contribution of this paper is providing a credible estimate of how unemployed workers react to an increase in the provision of liquidity and estimating the liquidity-to-moral hazard ratio. Learning about this ratio is fundamental to evaluate the welfare effects of unemployment insurance policies; and to guide policy makers in setting a reasonable and close to optimal generosity level of unemployment benefits. To the best of my knowledge only Chetty (2008) and Landais (2014) estimate this ratio using data from the US. This is then the first paper to estimate the size of this ratio in a developing country, in which informal labor markets are prevalent. Furthermore, since the estimates here presented do not rely on policy changes, which are not frequent, they can deliver timely estimates from year to year. Therefore, these could be used by policy makers on a constant basis to evaluate the policy and optimally adjust UI over time.

The paper is organized as follows. Section 2 presents the theoretical background with the goal of clearly stating the parameters of interest to be estimated in the empirical section. In section 3 , the empirical analysis of the bonus policy is presented. There the liquidity effect is estimated. In section 4, variations in potential duration of UI benefits due to tenure are exploit in order to estimate the overall effect of UI on re-employment probabilities. This effect is a mix of a liquidity and a moral hazard effect. Section 5 takes the estimates from the two empirical sections and, based on the theory described in the next section, estimates the liquidity-to-moral hazard ratio. Section 6 concludes and discuss the main results.

\section{Theoretical Background}

The main goal of this work is to estimate the liquidity-to-moral hazard ratio as defined by Chetty (2008). Namely, it is defined by the following ratio:

$$
\rho=\frac{-\left.\frac{\partial s_{0}}{\partial a}\right|_{B}}{\left.\frac{\partial s_{0}}{\partial w}\right|_{B}}
$$

where $s_{0}$ defines the probability of finding a job in the first period of the unemployment spell, $B$ is the potential duration of benefits, $a$ is an annuity payment, $w$ is the wage rate and $\left.\frac{\partial s_{0}}{\partial a}\right|_{B}=\sum_{t=0}^{B-1} \frac{\partial s_{0}}{\partial a_{t}}$ and $\left.\frac{\partial s_{0}}{\partial w}\right|_{B}=\sum_{t=0}^{B-1} \frac{\partial s_{0}}{\partial w_{t}}$. The numerator is the liquidity effect: the marginal effect of providing liquidity to the unemployed during $B$ periods on the probability of finding a job at the first period of spell. The denominator defines the moral hazard: the marginal effect of increasing the pay-off of leaving 
unemployment (without providing liquidity) on the probability of finding a job at the first period of spell.

By exploiting the bonus policy, it is possible to estimate $\frac{\partial s_{0}}{A_{0}}$ : how the probability of finding a job at the first period of spell changes due to a cash grant at the start of the spell. From this result it is possible to recover the first term of the formula by applying the approximation that $-\left.\frac{\partial s_{0}}{\partial a}\right|_{B} \approx-B \frac{\partial s_{0}}{\partial A_{0}}$ as discussed in Chetty (2008). This fact should not be a reason for any concern since $\frac{\partial s_{0}}{\partial A_{t}}$ should not vary over the first $B$ months of the spell if the budget constrain does not bind. Moreover, even if it does bind, it should not vary much since potential duration in Brazil varies only from 3 to 5 months, which is a fairly short period.

From the RDD analysis on potential duration, it is possible to recover $\frac{\partial s_{0}}{\partial b_{t}}$ : the effect of raising potential duration by one period, which is equivalent to raising benefit level from zero to $b$ at the point where duration increases. This effect is a composition of moral hazard and liquidity reactions by the workers. In order to find which share of it is due to moral hazard, I use the following results from Landais (2014) to isolate the moral hazard effect from combining this paper's estimates of $\frac{\partial s_{0}}{\partial A_{0}}$ and $\frac{\partial s_{0}}{\partial b_{t}}$ :

$$
\frac{\partial s_{0}}{\partial b_{t}}=\frac{\partial s_{0}}{\partial A_{0}}-S_{1}(t) \frac{\partial s_{0}}{\partial w_{0}}
$$

and

$$
\left.\frac{\partial s_{0}}{\partial w}\right|_{B}=\frac{\partial s_{0}}{\partial w_{0}} \sum_{t=0}^{B-1} S_{1}(t)
$$

where $S_{1}(t)$ defines the survival rate in unemployment until period $t$ conditional on being unemployed at period 1. These formulas are an intertemporal extension of Chetty (2008)'s key decomposition:

$$
\frac{\partial s_{t}}{\partial b_{t}}=\frac{\partial s_{t}}{\partial A_{t}}-\frac{\partial s_{t}}{\partial w_{t}}
$$

This original (intratemporal) form describes how the marginal effect of an increase in UI benefits is a composition of a liquidity and a moral hazard effect. First, higher benefit level relaxes the budget constrain of unemployed workers, increasing liquidity, which causes lower search effort at the same period: the liquidity effect $\left(\frac{\partial s_{t}}{\partial A_{t}}\right)$. Second, higher benefit level also creates a moral hazard problem because unemployment benefits are the opportunity cost of finding a job: once workers find a new job, unemployment insurance is suspended. This mechanism also causes them to search less intensively: the moral hazard effect $\left(\frac{\partial s_{t}}{\partial w_{t}}\right)$. 
Equation (2) simply describes how this decomposition works in a intertemporal fashion which is discussed at lenght in Landais (2014). Equation (3) specifically describes how moral hazard is connected over time. It states that the total moral hazard effect of a full decrease in the pay-off profile of finding a job for $B$ periods (similarly to what a raise in UI benefits for $B$ periods does) is equivalent to the moral hazard effect of decreasing the pay-off of finding a job at a single period adjusted by survival probabilities.

Since $\frac{\partial s_{0}}{\partial b_{t}}, \frac{\partial s_{0}}{\partial A_{0}}$ and $S_{1}(t)$ are known, it is possible to derive $\frac{\partial s_{0}}{\partial w_{0}}$ using (2). Then, (3) allows me to derive the moral hazard effect as in the denominator of (1). Thus, using (2), (3) and the approximation $-\left.\frac{\partial s_{0}}{\partial a}\right|_{B} \approx-B \frac{\partial s_{0}}{\partial A_{0}}$, the liquidity-to-moral hazard ratio is estimated as:

$$
\rho=\frac{-\left.\frac{\partial s_{0}}{\partial a}\right|_{B}}{\left.\frac{\partial s_{0}}{\partial w}\right|_{B}}=\frac{-\frac{\partial s_{0}}{\partial A_{0}}}{\frac{\partial s_{0}}{\partial w_{0}} \bar{S}_{1}^{B}}
$$

where $\bar{S}_{1}^{B}$ is the average survival rate between time 1 and $t$ conditionally on being unemployed at time 1. The intuition behind this strategy to estimate the liquidity-to-moral hazard ratio is simple. The effect of an increase in unemployment benefits on labor supply is a composition of liquidity and moral hazard effects. Once workers are granted with more unemployment benefits, they take longer to find a new job for two reasons. First, they are less liquidity constrained and thus they do not need to search too intensely for a new job. Second, UI benefits create a moral hazard problem because it increases the opportunity cost of leaving unemployment: workers lose their benefits once re-employed. In this paper, I use the "bonus policy" to estimate the first (liquidity) effect and the UI schedule to estimate the composed overall effect of increasing benefits. The strategy to disentangle the moral hazard effect is taking the second result of the UI extension (liquidity + moral hazard) and discounting it from the liquidity effect estimated from the "bonus" policy. The formula from above is also composed of a survival rate term in order to account for the fact that the "bonus" policy takes place at the beginning of the spell while potential duration increases benefit level at the end of the spell.

\section{Empirical Analysis I: Liquidity Effect}

In this section, I present the empirical analysis used to estimate the effects of liquidity provision on the probability that unemployed workers find a job at the beginning of their spells.

\subsection{The "Bonus Policy"}

The "Bonus Policy" (Abono Salarial) was introduced in Brazil by the Federal Law 7.998 of 1990 and is in place since then. The policy is financed by a fund supported by compulsory contributions from firms in the private sector. Contributions depend solely on gross revenues and are not related whatsoever to 
how firms manage their workforce. Every year, it grants a sum equal to one monthly minimum wage to all workers in the country satisfying the following conditions: (i) have been employed at any firm in the private sector for at least 30 days in the year before the payment year ${ }^{2}$; (ii) average monthly earnings in the year before payment has not exceed two monthly minimum wages in that year; and (iii) have started working in the formal labor market at least five years before the payment year. The cash grant does not depend on the workers' labor market outcomes in the payment year and, hence, is paid both to workers who happen to be employed and unemployed at the moment of the payment.

The exact timing of the payment during a year ranges from July to November and can happen in three different ways: (i) workers who hold an account at the state controlled bank (Caixa Economica Federal) responsible for the payments are paid in July; (ii) those employed at firms which have an agreement with the public controlled bank responsible for the payments are paid from July to August, and (iii) those not entitled to the two previous payment channels can withdraw the bonus starting from August to November according to their month of birth, and are able to do so until June of the next year.

\subsection{Data and Identification Strategy}

The data used for both empirical analyses is the RAIS (Relação Anual de Informações Sociais) for the years from 2005 to 2012. It is a linked employer-employee administrative dataset covering the whole Brazilian formal labor market. It contains more than 50 million employment contracts in each year. It allows one to track workers' formal employment history over the years and contains information such as earnings, tenure, years of schooling, race, gender, birth date and weekly workload, among others.

To estimate the effect of the grant on re-employment probabilities cleaning from confounding factor, I apply a regression discontinuity design to exploit the condition that only workers earning up to two minimum wages in the previous year are eligible to the grant (eligibility condition (ii)). Because the data contains no explicit variable informing on workers' eligibility for the cash grant over the years, it is necessary to manually identify these workers. The sample for the analysis is built by first restricting the dataset to workers who have worked at least 30 days in the year previous to the bonus payment (eligibility condition (i)), for each year from 2005 to 2011. Notice that I can only consider grants paid from 2006 to 2012, since eligibility criteria (i) and (ii) require data from the previous year. Second, I consider only workers who had only one employment contract during each eligibility year (the year before payment). This is to avoid the need to calculate average earnings in between jobs within a year. Such calculation is not exactly trivial because tenure in each job is different and minimum wage varied in the middle of some years while data only informs average earning (also in terms of minimum wages) in the year for each labor contract. Henceforth, by using this restriction, it is possible to rely on the data on average yearly earnings, already calculated in terms of minimum wages, without the need to average

\footnotetext{
${ }^{2}$ Workers hired by individuals are not entitled to the bonus.
} 
it over different employment contracts. It ensures precision on the running variable for the RDD, which is based exactly the average earnings in minimum wages in the eligibility year.

It is also reassuring to know that the state controlled bank responsible for identifying and paying eligible workers rely exactly on the same dataset used in this work. This fact ensures that even in the extreme case where there is imprecision in this dataset (which is based on compulsory information reported by firms) affecting the assignment of the bonus, this will be the actual data used by the bank to effectively concede the cash grant. In other words, there is no asymmetry between the data used in this work and the data used by the state controlled bank to assign the cash grant in each year. In order to avoid considering workers too far away from the threshold, I drop workers with average monthly earnings in the eligibility year higher than 3 minimum wages or lower than one minimum wage. ${ }^{3}$

At this point, I further restriced the dataset to workers who are dismissed against their will in the payment year of the bonus. ${ }^{4}$ I do not consider other forms of job termination to avoid endogeneity problems due to voluntary job loss: for example, workers may quit because they are entitled to the bonus. Such a mechanism would cause self-selection and could bias the results. Furthermore, I restrict the sample to workers displaced only in the month of June, which is just the month before the payment starts. In such a way, I avoid considering workers who become unemployed after receiving the bonus. This helps preventing endogeneity of lay-off probabilities to the actual payment of the grant.

Given these restrictions, the sample contains only workers who satisfy eligibility condition (i) and may or not satisfy the eligibility condition (ii) according to their average earnings in the previous year. As regards eligibility condition (iii), there are some workers in the sample who do not satisfy this condition. Namely, those who have first entered the (formal) labor market within four years before the payment. Since the data does not contain explicit information on the date which workers first enter the labor market, the only way to verify this condition would be restricting the analysis only to the payment years of 2010, 2011 and 2012. For these years, it is possible to check whether workers were already registered in the labor market five years before given the span of time available in the data. Such procedure however seriously decreases the number of observations in the dataset because it only considers three years of payment restricted to workers who were not unemployed or out of the labor force in the few years which can be used to verify this condition: 2005, 2006 and $2007^{5}$. This would imply in a significant loss of observations and statistical power in the analysis. Hence, since the share of workers in a given year who have first entered the labor market within the last four years is likely to be small, I decide to use the

\footnotetext{
${ }^{3}$ Workers in the dataset can have average monthly earnings below the monthly minimum because not all of them work full-time.

${ }^{4}$ Workers dismissed against their and without a just cause, which is by far the most typical form of termination in Brazil.

${ }^{5}$ More precisely, I can only recall eligible workers for the cash grant in 2010 who were working in 2005 . Therefore, all eligible workers to the cash grant in 2010, satisfying eligibility condition (iii) (who have entered the labor market before 2005), and who have not worked in the year of 2005 can not be identified.
} 
whole sample for all years of bonus payment (2006-12) in which some workers fail to satisfy eligibility condition (iii). In the RDD analysis, those should behave in the same way around the threshold and, if their share is large enough, it will bias estimates toward zero. Therefore, estimates on the whole sample used here should be a lower bound. In order to get a better sense of the actual effect, results on the restricted sample for the years of 2010, 2011 and 2012 are also reported and discussed in the next subsection: even though they are less precise, they are still valuable to better estimate the size of the actual liquidity effect.

Another point to highlight is that even though it is not possible to observe whether eligible workers actually withdraw the grant, data from the Ministry of Labor shows that take-up rate is around $95 \%{ }^{6}$ Hence, every year the vast majority of entitled workers do receive the grant. A further point to remark is that it is only known that all beneficiaries have the grant available from July to November, without the precise date. It means that the cash grant is made available over the first five months of the spell. It is also true that a fair share of workers are likely to receive it on the first two months of unemployment (July and August) because the payment methods (i) and (ii) should cover a non-negligible share of

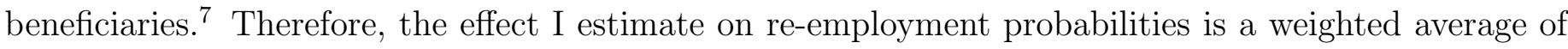
liquidity provision over the first five months of the spell, with higher weights for the first two months. However, this should not be a reason of any concern for two reasons. First, $\frac{\partial s_{0}}{\partial A_{t}}$ should be close to constant over the beginning of the spell, for the reasons discussed in section 2. Second, even if it happens not to be close to constant, results will be an estimate which is closer to $\left.\frac{\partial s_{0}}{\partial a}\right|_{B}=\sum_{t=0}^{B-1} \frac{\partial s_{0}}{\partial a_{t}}$, which is the actual statistic of interest arising from the background model.

In summary, the final sample contains workers who become unemployed against their will from 2006 to 2012 in the month of June, and have worked at least for 30 days in the previous year in a single employment spell. Those in the sample who had earned on average less than two minimum wages in the previous year are entitled to the cash grant, which is made available for them from July to November, in each year. ${ }^{8}$ Summary statistics are presented in table 2. On this sample, I run the RDD analysis using a local polynomial spline specification as in:

$$
Y_{i}=\sum_{p=0}^{P}\left[\gamma_{p}(w-2)^{p}+\beta_{p}(w-2)^{p} . D\right]+Z \alpha+\epsilon_{i} \text { where }|w-2| \leq h
$$

\footnotetext{
${ }^{6}$ This data is available on http://portal.mte.gov.br/imprensa/mais-de-1-milhao-nao-sacaram-abono-salarial/ palavrachave/abono-salarial-prazo-final.htm

${ }^{7}$ It is hard to know exactly the number of payments made according to each category. News found on the internet suggest that, in 2007, 3.8 out of 11.1 million bonus were paid by the first two methods http://www. endividado. com. br/ noticia_ler-17173, correntista-caixa-recebe-abono-do-pis-partir-hoje.html

${ }^{8}$ except for those who do not satisfy eligibility condition (iii), which should represent a small share of all these workers. This issue is more extensively discussed in the results' section.
} 
where $Y_{i}$ is an outcome of interest, $w$ is the worker's average earnings in the (previous) eligibility year in minimum wages, $D$ is a dummy taking value 1 for $w-2>0, Z$ is a set of control variables including tenure at last and previous job, average earnings in the year, dummy variables for reaching minimum tenure requirement for UI, male, and for each category of schooling, race, industry and weekly hours of last and previous job, dismissal type at previous job and decile of age at dismissal date. The parameter of interest is $\beta_{0}$. It estimates the discontinuity when workers around the threshold are no longer eligible for the bonus. Thus, $-\beta_{0}$ identifies the local average treatment effect (LATE) of providing the cash grant to workers around the threshold. In the main specification, I use a local linear polynomial $(p=1)$ which is the most common in the literature. It is also in line with Gelman and Imbens (2014) which suggests that higher order polynomials should be avoided in RD designs. As regards the bandwidth choice $h$, I use the selector proposed by Imbens and Kalyanaraman (2011). ${ }^{9}$

As standard procedure in RDD applications, I provide two main tests to assess the validity of the design. First, I employ the McCrary (2008) test for discontinuity in the density of the assignment variable, which aims to identify whether there is manipulation in the treatment. Second, I test whether pre-determined covariates evolve continuously around the threshold using the specification in (6). Moreover, to better evaluate whether any potential imbalances in covariates around the threshold may affect the outcomes of interest, I create a linear prediction for the main outcomes here analyzed by regressing each of them on a rich set of covariates: quintile of average earnings in the previous year, decile of age at hiring and dismissal, employment duration in the payment year, and dummies for each month of tenure in the last and previous job, industry of last and previous employer, separation cause at previous job, race, gender, weekly hours of work, year, calendar month of dismissal and federal state (27). Then, using (6), I test whether these predictions evolve continuously around the threshold.

I notice that it is possible to identify some small but visible bunching of earnings at two minimum wages. This may happen for two reasons. First, it is possible to observe some heaping of observations at multiples of minimum wages in the data, probably because it works as a reference point for wage bargaining. Second, it might happen because firms and workers agree to manipulate earnings in order to allow workers to receive the bonus. The second reason is one of more concern since it could compromise randomization around the threshold. To deal with that I drop workers whose average earnings lie exactly at this point. As one key advantage of RD designs is that identification assumptions are testable, there is no need to take by grant that this strategy works. In the next subsection, I show that this procedure is enough to ensure the balance of a rich set of covariates around the threshold and that the assignment variable displays no discontinuities around the cut-off. The intuition of this procedure is also similar to the one proposed by Barreca et al. (2015) which studies heaping issues in RD designs. They show that even when heaping is endogenous, it is still possible to estimate the causal effect of interest by

\footnotetext{
${ }^{9} \mathrm{I}$ do not attempt to implement the selection procedure proposed by Calonico et al. (2014) because it is extremely computationally time consuming in a large dataset like the one used here.
} 
dropping the points of heaping. Their key consideration is that in this case the estimated effect is the local average treatment effect (LATE) on the non-heaped types. Since in our case there is bunching at only one point and it is fairly small, the LATE recovered represents quite well the population of workers around that threshold.

\subsection{Results}

Density Test Before turning to the results, I present evidence that the density of the running variable evolves continuously around the two minimum wages threshold. Figure 1 displays the density of average earnings with a third degree polynomial fit, selected by minimizing the Akaike Criterion. The graph clearly suggests that there is no discontinuity around the cut-off point. This impression is supported by the McCrary density test reported in the same figure, which cannot reject the null hypothesis of no discontinuity.

Graphical Evidence Figure 2 displays how the probability of re-employment within 8 weeks $\left(s_{0}\right)$ and overall unemployment duration evolves around the cut-off. ${ }^{10}$ The top panel shows a clear discontinuity on $s_{0}$, suggesting that workers receiving the bonus (left side of the cut-off) are less likely to exit unemployment at the beginning of the spell. At the bottom panel, the cash grant seems not to affect the overall duration of unemployment. It is worth noticing that this graph is also fairly more noisy, what might be a result of the large average duration of the unemployment spell (around 51 weeks).

In figures 3-4 it is possible to observe how a variety of covariates evolve around the threshold. All of them seem to evolve clearly continuously around the threshold. Perhaps the only exception is tenure at previous job which displays a negative discontinuity to the right side of cut-off. In the regression results, I discuss whether this discontinuity is either statistically or economically significant and if it might be driving results. Overall, I see the graphical evidence on this rich set of covariates as clear evidence in favor of the validity of the design.

Regression Results Table 3 shows regression results for both outcome variables and pre-determined covariates. I report both results from a specification without controls and one with controls. Comparing them provides insight on the validity of the design as one expect results not to change much with the inclusion of pre-determined covariates if the design is valid. Both specifications indicate that the probability of exiting unemployment at the beginning of the spell is $0.5 \%$ lower on the left side of the cut-off. It thus suggests that providing workers with a cash grant equal to one monthly minimum wage decreases the probability of re-employment within eight weeks by half percentage point. This result is statistically significant at the $1 \%$ level in both specifications. Instead, results on the full duration of

\footnotetext{
${ }^{10}$ I choose to define $s_{0}$ as the probability of re-employment in the first eight weeks of spell. Shorter definitions yield similar point estimates but imply in a significant loss of precision.
} 
unemployment yield a positive value significant at the $10 \%$ level which is not robust to the inclusion of controls. Thus, this evidence, which also goes the theory, is not much conclusive and should be interpreted with extreme caution.

Still in the same table, results on the pre-determined covariates point that the seemingly discontinuity on tenure at previous job turns out not to be statistically significant. There are however four statistically significant discontinuities in tenure at last job, years of schooling, gender and age at dismissal. The last three are arguably not economically significant as the size of the discontinuity represents an imbalance of only 0.063 years of schooling, $0.4 \%$ in the probability of being a female and 0.246 age years of difference. The discontinuity estimate on tenure at last job instead is moderate (around two weeks) and could compromise the design. Six months of tenure constitutes the minimum eligibility requirement (MER) for unemployment benefits and UI potential duration increases from 3 to 5 months according to tenure. Hence, the main suspicion is that the interaction of tenure imbalances with UI eligibility and potential duration could directly affect unemployment outcomes.

A first evidence which suggests that this is not the case is the fact that there is no significant discontinuity on the probability of reaching MER. It suggests therefore that the same share of workers on both sides of the threshold are eligible for unemployment insurance. Second, if anything, workers on the right side of the threshold (not granted with the bonus) are dismissed with higher tenure and thus might have longer UI benefits and slightly larger severance payments. Because longer benefits and larger severance payments could only cause a decrease in the probability of exiting unemployment at the beginning of the spell, such imbalances could only bias the result on $s_{0}$ downwards, while the actual effect found is positive. Therefore, even if it is actually the case that there is a bias, in the worst case scenarium estimates represent a lower bound of the effect.

To gain a sense of how these imbalances could actually affect the results in any economically meaningful way, I create a linear prediction by regressing both outcomes on an extremely rich set of pre-determined covariates, as discussed in the previous subsection. Then, I test whether these predicted values are discontinuous around the cut-off to gain insight on how these imbalances could bias the results. In the same table, it is reassuring to see the the linear prediction of $s_{0}$ presents no statistically significant discontinuity and, if anything, the sign of the bias goes to an opposite direction while its size is clearly of a smaller order of magnitude than the actual discontinuity found in $s_{0}$. I interpret this evidence as a strong sign that results on this variable are not biased in any economically significant order of magnitude, and, if anything at all, estimates represent a lower bound very close to the actual value.

On the other hand, the same exercise on the predicted overall duration of unemployment strongly suggests a sizable discontinuity on this outcome and that such results should be interpreted with much caution. As one could only expect individuals with less liquidity to take less time to exit unemployment, 
this imbalances in predicted unemployment duration may also explain why the estimated discontinuities on both specifications are positive, contrary to theory. It also worth noticing that in the specification with controls, the discontinuity in unemployment duration is no longer statistically significant, suggesting that adding controls to the regression effectively helps mitigating biases driven by imbalances in (observable) covariates.

Heterogeneity At this point I show that the need for liquidity is heterogeneous for groups of workers displaced at different tenure ranges. I split the sample in three groups and repeat the analysis performed in the full sample. The first and most liquidity constrained group (0-5.8 tenure months - low tenure group) contains dismissed workers who do not the reach MER and therefore are not entitled to UI benefits. ${ }^{11}$ At the second group are workers dismissed with tenure ranging from 6 to 60 months (mid tenure group). All these workers reach MER and are also entitled to larger severance payments which vary from 0.8 to 7 times their average monthly earnings. At the third and less liquidity constrained group are workers dismissed with more than 60 months of tenure (high tenure group). These workers are all entitled to unemployment benefits with the longest potential duration (5 months) and receive severance payments starting from 7 times their average monthly earnings.

Figure 5-7 show the graphical evidence on outcomes of these three groups, while covariates are displayed in the appendix figures A1-A6. The evidence in figure 5 for the low tenure group is striking: workers granted to the bonus are clearly less likely to exit unemployment right away and seem to remain on average two weeks longer unemployed. For the mid tenure group discontinuities are less clear but it still seems that the cash grant provision makes workers slightly less likely to find a new job at the beginning of the spell, suggesting that the liquidity provision still plays a role for these workers. For the high tenure group, there seems to be no discontinuity in $s_{0}$ and a negative jump on the duration of unemployment, even though the graph displays fairly more noise.

Table 4 display regression results on the three groups without and with controls, respectively. Results on $s_{0}$ indicate that low tenure group is by far the most sensitive to the cash grant, as one could expect given that these workers are not entitled to unemployment benefits and have very low severance payments. Providing one monthly minimum wage for these workers decreases their probability of finding a new job within eight weeks by $1.3 \%$ and increases unemployment duration by roughly two weeks. Instead, the same effect on the mid tenure group, is of only $-0.34 \%$ on $s_{0}$ and not statistically significant on unemployment duration after controls are added. On the high tenure group, neither of the effects are statistically significant, even though one should consider that the estimations are noisier. Balance on covariates are overall good and results on the linear predictions indicate that, if at all, any bias on $s_{0}$ goes the opposite directions of the results and yield a smaller order of magnitude. As regards

\footnotetext{
${ }^{11}$ Since tenure months in the data has a 30 days reference month with one-digit precision, I exclude workers with 5.9 months of tenure because some of them actually reach MER, which is counted according to calendar months.
} 
unemployment duration, predicted discontinuities are larger, especially for the mid tenure group, and the direction of the bias is always on an opposite direction to the one suggested by the theory.

At this point, I address the limitation that some workers in the sample used so far are not eligible to the bonus due to eligibility condition (iii): those who have first entered the labor market within less than 5 years are not entitled, as discussed before. Hence, estimations discussed above represent a lower bound of the effect. To deal with that and better assess the actual absolute value of the effect, I further restrict the sample. I now consider only those workers who surely satisfy the eligibility condition (iii), i.e., who can be recalled working in the data at least five years before the grant payment. This procedure limits the analysis to only three years of bonus (2010, 2011 and 2012) for workers who are identified to have worked through the years of 2005, 2006 and 2007. Since the number of observations strongly decreases and much statistical power is lost, I redefine $s_{0}$ as the probability of finding a new job within twelve weeks instead of eight to improve precision.

Table 5 display the results for the linear specification without and with controls. Estimates on predicted $s_{0}$ in this specific sample point for a statistically significant and not small negative bias this outcome. It is probably the reason why estimates on $s_{0}$ without controls point for a non statistically significant effect which is smaller in magnitude than the one previous found on the full sample $(0.43 \%$ versus $0.5 \%$ ). The estimated effect on $s_{0}$ increases to $0.064 \%$ once controls are added and are border line statistically significant at the $10 \%$ level. They are about $20 \%$ larger than the same estimates on the full sample.

Table 6 shows results on tenure groups without and with controls. As expected, the estimated effects on $s_{0}$ increases in the specification with controls, again by about $20 \%$, but results lose some statistical significance. Nevertheless, they are still border line significant at the $10 \%$ level for the low and mid tenure groups: t-statistics are 1.52 and 1.34 respectively. In appendix table B1, I provide the same analysis with a second degree polynomial which displays stronger results. Effects on $s_{0}$ are found to be larger and t-statistics increase to 2.12 and 1.57 for the low and mid tenure group respectively. Overall, point estimates of the linear and quadratic specifications suggest that the cash grant decreases the probability of exiting unemployment at the beginning of the spell by between $1.6 \%$ and $2.4 \%$ for the low tenure group, by between $0.67 \%$ and $0.87 \%$ for the mid tenure group and are statistically insignificant for the high tenure group. I interpret these as the best guesses of the true liquidity effect. Hence, the analysis on the liquidity-to-moral hazard ratio is based on these point estimates.

I draw four main conclusion from these results. First, unemployed workers are indeed liquidity constrained since their probability of exiting unemployment at the beginning of their spell reacts to the cash grant provision, which yields no moral hazard. Second, workers dismissed with low tenure and not entitled to UI react very strongly to the cash grant, and thus are very liquidity constrained. Third, the 
mid tenure group, which is eligible for UI and larger severance payment, still displays a mild reaction to the cash provision, indicating that they are still liquidity constrained to a fair extent. Fourth, since the low tenure group (not entitle to UI) is found to be way more liquidity constrained than the mid tenure group (entitled to UI), it suggests that UI provision is succeeding on its goal of providing liquidity for those in need.

\section{Empirical Analysis II: Potential Duration Effect}

In this section, I present the empirical analysis exploring the UI potential duration schedule. The goal is assessing how the probability of exiting unemployment at the beginning of the spell reacts to UI potential duration extensions.

\subsection{UI and Potential Duration Schedule in Brazil}

Unemployment Insurance in Brazil is administered at federal level and was introduced by the Federal Law 7.998 in 1990. Important changes were implemented in 1994 by the Federal Law 8.900, which defines all the relevant features of the system for the period analyzed in this paper (2005-2012). ${ }^{12}$ As is the case for the Bonus Policy, the system is finance by a compulsory contribution which is a percentage of firms' gross revenues and by no means is related to firms' behavior as regards labor force management. Therefore, there is no experience rating in place. To be eligible for unemployment benefits workers must satisfy the following conditions: (i) have worked continuously in the last 6 months (MER); (ii) have been dismissed against their will without a just cause, which is the most typical form of dismissal in Brazil ; there should be at least 16 months differences between the lay-off date and the date of the last previous lay-off which the worker used to claim UI benefits in the past, if it is not his first claim.

The replacement ratio is $100 \%$ for workers earning close to minimum wages and decreases up to $68 \%$ for workers who are just at the benefit cap, whose earnings are equivalent to 2.75 minimum wages. From this point, replacement ratios steadily decrease for higher earnings since a benefit cap is in place. Maximum duration varies from three to five months according to tenure as in the following table:

Table 1: Potential Duration Assignment Rule

\begin{tabular}{cc}
\hline Months worked in the last 36 months & Months of Benefit \\
\hline from 6 to 11 & 3 \\
from 12 to 23 & 4 \\
More or equal 24 & 5 \\
\hline
\end{tabular}

\footnotetext{
${ }^{12}$ At the beginning of 2015 new significant changes which are still being implemented were introduced.
} 


\subsection{Data and Identification Strategy}

In order to assess the effect of increasing potential duration on $s_{0}$, I apply again a regression discontinuity design to exploit the fact that workers laid-off with more than 24 months of tenure are eligible to five months of benefits instead of four. It is not possible to exploit neither the 6 nor the 12 months threshold, as similarly noticed by Gerard and Gonzaga (2013) who follow the same RD strategy to estimate UI effects on a different set of unemployment outcomes. When workers become eligible for UI at 6 months tenure, there is a large spike in lay-off hazard rates which causes selection around this cut-off. Around the 12 months tenure, when potential duration increases from 3 to 4 months, there is a sharp decrease in lay-offs because legislation imposes higher administrative costs for firing workers with more than one year of tenure.

Gerard and Gonzaga (2013), who use administrative data on the actual payment records of the UI system in Brazil, report that the potential duration rule presented above is not perfectly enforced. Even though the law only grants five months of potential duration to displaced workers with tenure higher than 24 months, in practice, a share of beneficiaries displaced with tenure between 22 and 24 months are granted with 5 months of potential duration. As it would cause the RD analysis to fail because there is no actual discontinuity in the treatment around the 24 months, I apply here the same strategy suggested by Gerard and Gonzaga (2013). In the RD analysis, I set to the right of the cut-off workers who were displaced with 24 months and more, and to the left workers displaced with 22 months and

less. In such a way, on the right side of the threshold there are only workers eligible to five months of potential duration and on the left side are only workers eligible to four months of potential duration. For this strategy to succeed, workers around the 22 and 24 months thresholds should work as good counterfactuals to each other. As in any RDD, such requirement can be tested by checking for the existence of discontinuities in pre-determined covariates. As a further robustness check, I also provide results for two placebo thresholds around which there is no change in UI potential duration. Therefore, I implement the same procedure described above to compare workers displaced with 16 and 18 tenure months; and workers displaced with 30 and 32 tenure months.

In order to assess the effect of benefit extension on a similar group of workers, I build this second sample analysis departing from the sample used in the previous section. Thus I depart from a sample of workers who are displaced in the calendar month of June and who had average earnings in the previous year from one to three minimum wages in a single employment spell. Then I reduce the sample to workers which are closer to the $22^{-} / 24^{+}$months threshold by keeping in data only those displaced with tenure higher than 14 months and lower than 32 months. Since the effects found in the previous section are local effects for workers earning on average 2 minimum wages, I restrict again the sample to workers earning on average strictly more than 2 and less than 2.25 minimum wages in the previous year. By doing so, the RDD analysis recovers the effect of benefit extension on a group of workers which has very 
similar earnings and are not entitled to the bonus policy.

\subsection{Results}

Figure 9-10 show how covariates evolve around the $22^{-} / 24^{+}$tenure months threshold. It is comforting to see that covariates overall evolve clearly continuously across the threshold. It strongly suggests that workers displaced with just less than 22 tenure months are good counterfactuals for workers displaced with just more than 24 tenure months. The only variable which seems to be an exception is average earnings in the year of displacement which seems to be higher on the right side. It is however important to notice that this sample contains only workers who lie in an extremely narrow window of earnings: between 2 and 2.25 minimum wages in the previous years. Therefore any statistically significant imbalance in earnings has a very low potential to be large enough to cause any economically significant difference on outcomes.

This intuition is confirmed by the regression results displayed in table 7 . The only statistically significant imbalances are on earnings and age at dismissal, which are however economically small: only $13 \%$ higher earnings in terms of minimum wages (local average earnings is around $2.1 \mathrm{~m} . \mathrm{w}$.$) and$ roughly half a year in age difference. The same exercise done in the previous empirical analysis is repeated here: I assess whether imbalances in pre-determined covariates can predict discontinuities in $s_{0}$ and unemployment duration. The same table shows that discontinuities estimate are not significant neither for predicted $s_{0}$ or unemployment duration. Moreover, if there is any bias at all, it goes to the opposite direction to the estimated effect. Therefore, I interpret this evidence on the continuity of covariates and predicted outcome values as strongly supportive for the validity of the design.

On the other hand, as shown by figure 8, the graphical evidence on $s_{0}$ and unemployment duration is striking. There is a clear negative jump on $s_{0}$ and a clear positive discontinuity in unemployment duration, as one would expect from theory. Results in table 7 suggest that an extra month of potential duration decreases the probability of exiting unemployment within 8 weeks by $1.9 \%$, which is robust to the inclusion of controls. Results from the specification without controls point that unemployment duration increases by 2 weeks as potential duration is extended by a month. It yields a similar value to the one found by Landais (2014) with US data which points that an extra week of potential duration raises duration by around 0.4 weeks. This result on the full unemployment duration however should be taken with some caution as it is not robust to the inclusion of controls: in this regression the effect decreases by $50 \%$ and is no longer statistically significant.

In order to investigate whether these results are driven by the fact that the proposed design takes workers displaced with 22 tenure months as counterfactuals for those displaced with 24 months, I provide the following placebo test. I implement the same design at two thresholds in which there are no changes 
in UI potential duration. The first placebo test assess whether job finding rates of workers displaced with 16 tenure months are any different of those laid-off with 18 tenure months. The second placebo test repeats the same procedure for workers laid-off with 30 and 32 tenure months. These results are displayed in table B2. It is reassuring to see that, in absolutely all specifications, it is not possible to find any statistical significant result on $s_{0}$ in any of the two placebo tests. This strongly suggests that dropping workers displaced in between 22 and 24 months of tenure is not driving the results from above.

\section{Liquidity-to-Moral Hazard Estimates}

In the two previous section, I estimate the effect of providing liquidity and extending potential duration on the probability of re-employment at the beginning of the spell, $s_{0}$. The goal of this section is to use these estimates with the background theory from section 2 to estimate how large is the liquidity-to-moral hazard ratio in Brazil. I proceed in two steps. First, I use the estimates of $\frac{\partial s_{0}}{\partial A_{0}}$ and $\frac{\partial s_{0}}{\partial b_{t}}$ to recover the moral hazard effect $\frac{\partial s_{0}}{\partial w_{0}}$ by using equation (2). Second, I use the recovered moral hazard effect and liquidity effect estimated in section 3 to estimate the liquidity to moral hazard ratio by using equation $(5)$.

Before moving to this two step procedure, I define the specific preferred estimates which are used to evaluate the ratio. From section 3, the liquidity effect is estimated for three different groups split by tenure. Since the overall UI effect on $s_{0}$ is a local effect for workers displaced with around $22^{-} / 24^{+}$tenure months, I decide to use the liquidity effects estimated for the mid tenure group (from 6 to 60 tenure months at displacement). This avoids concerns that both estimates are taken from groups of workers which are too different. Furthermore, I use the liquidity effect estimates on the sample of workers which surely satisfy eligibility condition (iii) for the cash grant, as in table 6. These estimates do not suffer from a downward bias for the reasons discussed in section 3. Therefore, my preferred estimate for the liquidity effect is that a cash grant equal to one minimum wage decreases $s_{0}$ by $0.67 \%$ for these group of workers. Nevertheless, in a second specification I also report estimates of the liquidity-to-moral hazard ratio based on the liquidity effect found for workers of all tenures, as in table 5 with controls. As regards

$\frac{\partial s_{0}}{\partial b_{t}}$, my preferred estimate from table 7 is that $s_{0}$ decreases by $1.9 \%$ when potential duration is extended by one month. This is equivalent to increasing potential benefits in the fifth month of unemployment from zero to 1.5 minimum wages, since replacement ratio is around 0.75 for workers earning around 2 m.w..

At this point, I use these estimates to feed equation 2 and recover the moral hazard effect $\frac{\partial s_{0}}{\partial w_{0}}$, as shown by table 8 . Then, by using equation (5), the liquidity-to-moral hazard ratio is estimated. I find a ratio of $98 \%$ in the preferred specification and a similar value of $89 \%$ in the specification using the liquidity effect based on the sample with workers of all tenure groups. This estimate is very close to the one found by Landais (2014) which finds a ratio of $0.88 \%$ using data from the US. This means 
that roughly $50 \%$ of the marginal increase in duration when UI benefits are raised is due to liquidity constrains.

\section{Conclusion}

This paper exploits two different policies in Brazil to estimate the liquidity-to-moral hazard ratio. First, it exploits a bonus policy which grants some low-income earners with a cash grant to assess how unemployment outcomes react to the provision of liquidity. I find that providing a cash grant roughly equivalent to half of a monthly wage decreases the probability that unemployed workers find a new job within 8 weeks of spell by $0.65 \%$. Second, by exploiting the UI potential duration schedule, I estimate that an extra month of potential duration decreases the probability that unemployed workers find a new job within 8 weeks by 1.9\%. Then, I use results from Landais (2014) based in a partial equilibrium search model to put these estimates together and estimate the liquidity-to-moral hazard ratio in Brazil. I find this ratio to be close to 1, suggesting that half of the marginal response of unemployed durations to increases in UI are due to a liquidity effect.

This work extends the extremely scarce empirical evidence on the liquidity-to-moral hazard ratio, which is a key measure to evaluate the benefit side from providing unemployment insurance. An important advantage of the approach here proposed is that it is able to evaluate the liquidity-to-moral ratio without the need to rely on policy changes, which are infrequent. Therefore, it can serve policy makers as method to deliver timely estimates of this statistic over time.

To the best of my knowledge, this is also the first paper to evaluate this ratio in a developing country, where informality is often very high. The results found in this paper challenge the common suspicion that providing unemployment insurance in contexts of large informality is not beneficial to welfare as moral hazard is expected to be too high. The estimates presented in this paper show instead that moral hazard is actually not much different from previous figures found for the US, and, more importantly, the liquidity-to-moral hazard ratio seems to be about the same. A further relevant consideration is that this is not an artifact of local marginal effects due to differences in UI generosity between Brazil and the US. Both countries provide a similar potential duration and, if anything, replacement ratios are larger in Brazil. ${ }^{13}$

This work also complements results by Gerard and Gonzaga (2013). They show that since a large share of displaced workers in Brazil do not come back to the formal labor market, the efficiency-cost of providing UI is limited. They argue the most UI beneficiaries exhaust benefits independent of the

\footnotetext{
${ }^{13}$ Potential duration ranges from three to five months in Brazil while the average in the US is roughly 22 weeks in the sample used by Landais (2014). Replacement ratios in Brazil are as high as $100 \%$ for workers in the low-end of the earnings distribution and are still around $68 \%$ at the benefit cap, while in the US it roughly average $50 \%$ and rarely ever exceed $60 \%$.
} 
insurance provision and, therefore, the behavioral cost of increasing UI benefits is low. As they show that only this behavioral cost is detrimental to welfare, increasing UI generosity yields limited welfare costs. The open question which remains from their analysis is whether the welfare gains from consumption smoothing are not small in a context where informality is prevalent. The results presented here fill this gap and show that UI benefits from consumption smoothing are as large as previously found in the US. Taken together, they suggest that, at least on the margin, raising the generosity of unemployment insurance in Brazil could generate significant welfare gains. 


\section{References}

Barreca, A. I., J. M. Lindo, and G. R. Waddell (2015). Heaping-induced bias in regression-discontinuity designs. Economic Inquiry.

Calonico, S., M. D. Cattaneo, and R. Titiunik (2014). Robust nonparametric confidence intervals for regression-discontinuity designs. Econometrica 82(6), 2295-2326.

Chetty, R. (2008). Moral hazard versus liquidity and optimal unemployment insurance. Journal of Political Economy 116(2), 173-234.

Gelman, A. and G. Imbens (2014). Why high-order polynomials should not be used in regression discontinuity designs.

Gerard, F. and G. M. Gonzaga (2013). Informal labor and the cost of social programs: Evidence from 15 years of unemployment insurance in brazil. Available at SSRN 2289880.

Imbens, G. and K. Kalyanaraman (2011). Optimal bandwidth choice for the regression discontinuity estimator. The Review of Economic Studies, rdr043.

Landais, C. (2014). Assessing the welfare effects of unemployment benefits using the regression kink design. American Economic Journal: Economic Policy, forthcoming.

McCrary, J. (2008). Manipulation of the running variable in the regression discontinuity design: A density test. Journal of Econometrics 142(2), 698-714. 
Figure 1: Density of Previous Earnings around 2 m.w. Threshold

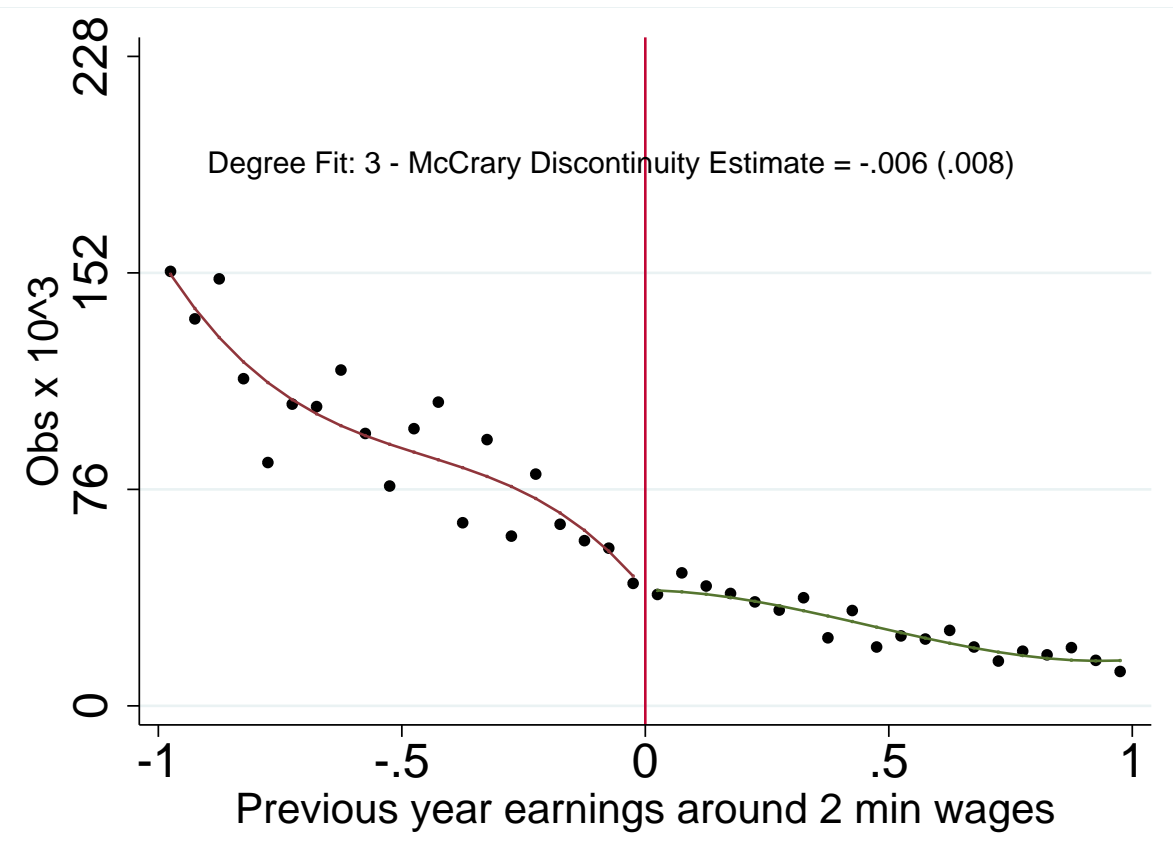

The graph displays how the density of previous earnings evolve around the threshold. At each side of the threshold, the density is approximated by the polynomial which minimizes the Akaike Criterion. The graph also displays the test statistic for the McCrary Discontinuity test. 
Figure 2: Unemployment Outcomes around 2 m.w. Threshold

\section{Outcome Variables}
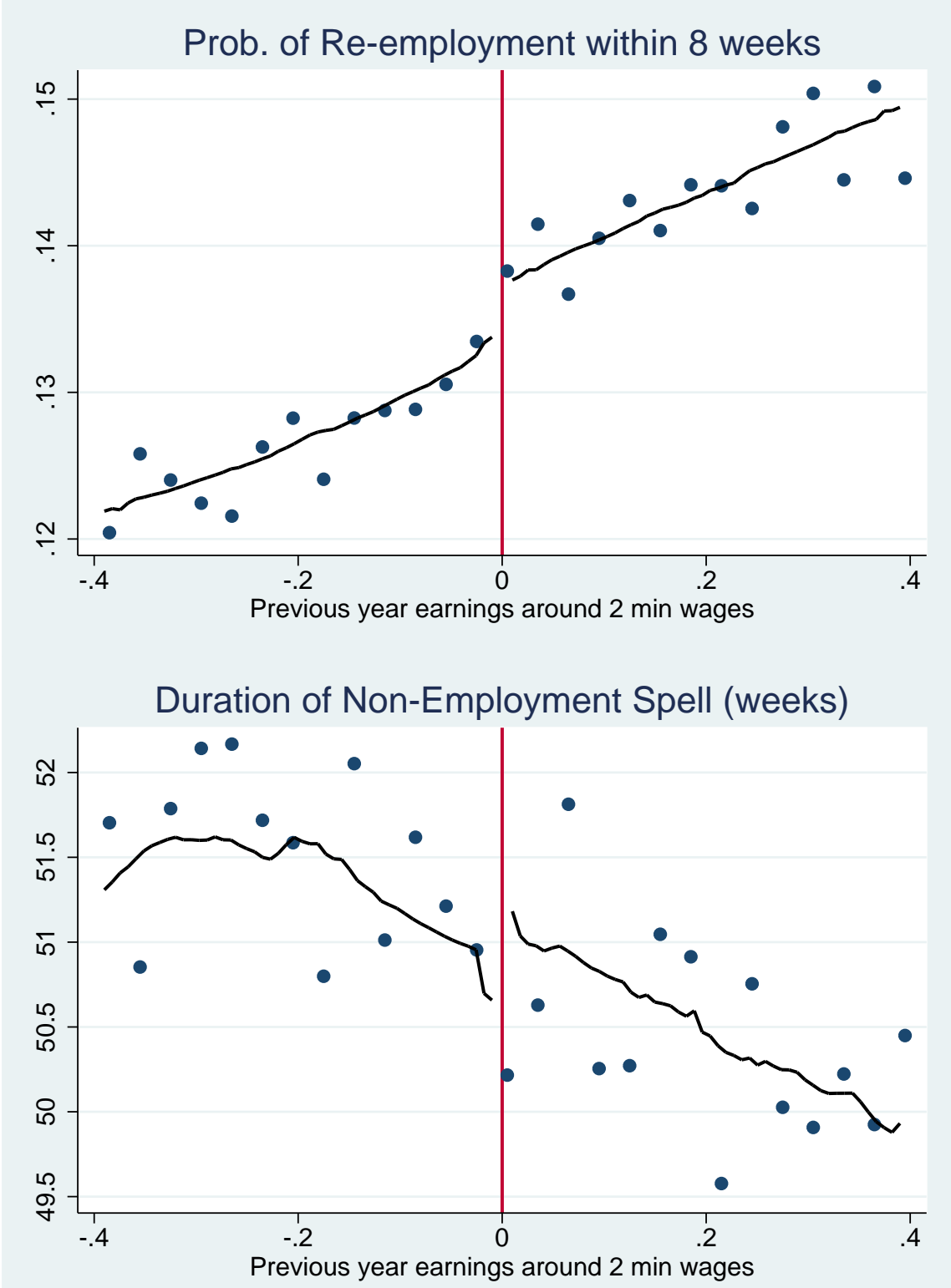

The graph displays how unemployment outcomes evolve around the threshold. At each side of the threshold, the conditional expectation function is approximated by a epanechnikov smoothed local linear polynomial with rectangular kernel. $s_{0}$ defines the probability of re-employment within 8 weeks. 
Figure 3: Covariates A around 2 m.w. Threshold

Continuity of Covariates $A$
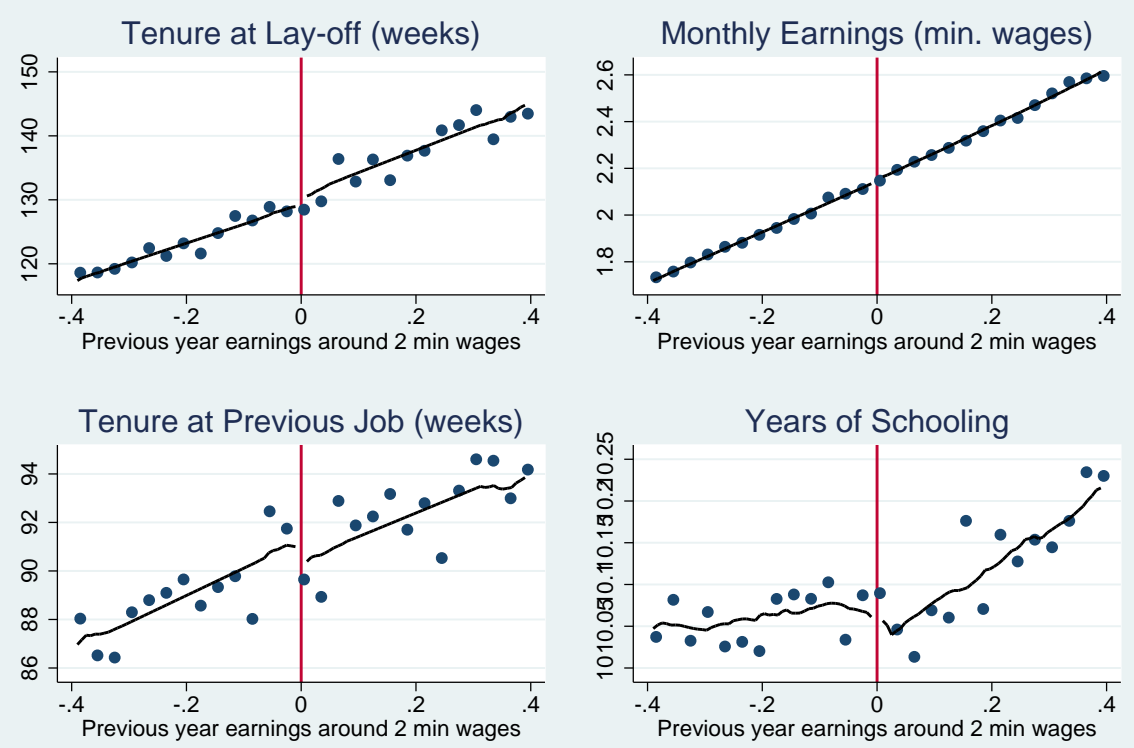

The graph displays how pre-determined covariates evolve around the threshold. At each side of the threshold, the conditional expectation function is approximated by a epanechnikov smoothed local linear polynomial with rectangular kernel.

Figure 4: Covariates B around 2 m.w. Threshold

\section{Continuity of Covariates B}
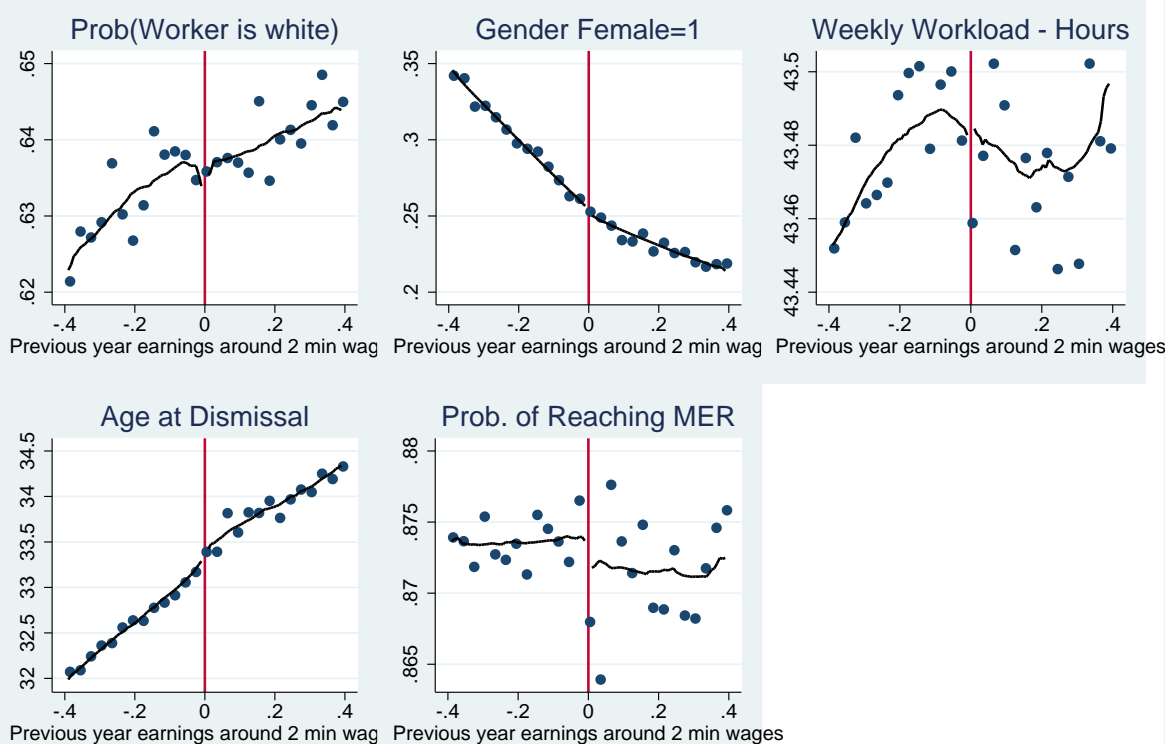

The graph displays how pre-determined covariates evolve around the threshold. At each side of the threshold, the conditional expectation function is approximated by a epanechnikov smoothed local linear polynomial with rectangular kernel. 
Figure 5: Unemployment Outcomes around 2 m.w. Threshold - Tenure 0-5.8 months

\section{Outcome Variables}

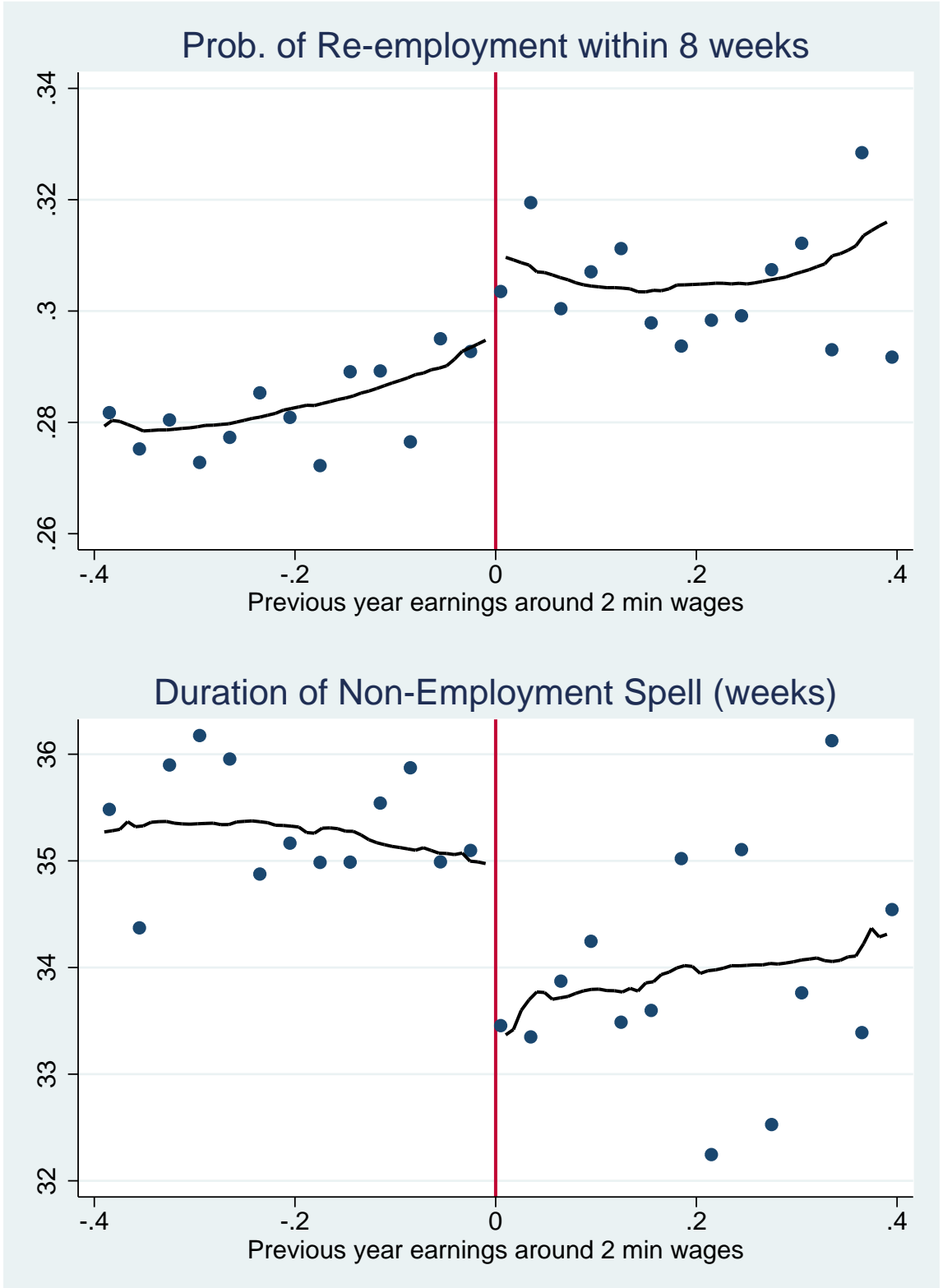

The graph displays how unemployment outcomes evolve around the threshold. At each side of the threshold, the conditional expectation function is approximated by a epanechnikov smoothed local linear polynomial with rectangular kernel. $s_{0}$ defines the probability of re-employment within 8 weeks. 
Figure 6: Unemployment Outcomes around 2 m.w. Threshold - Tenure 6-60 months

\section{Outcome Variables}

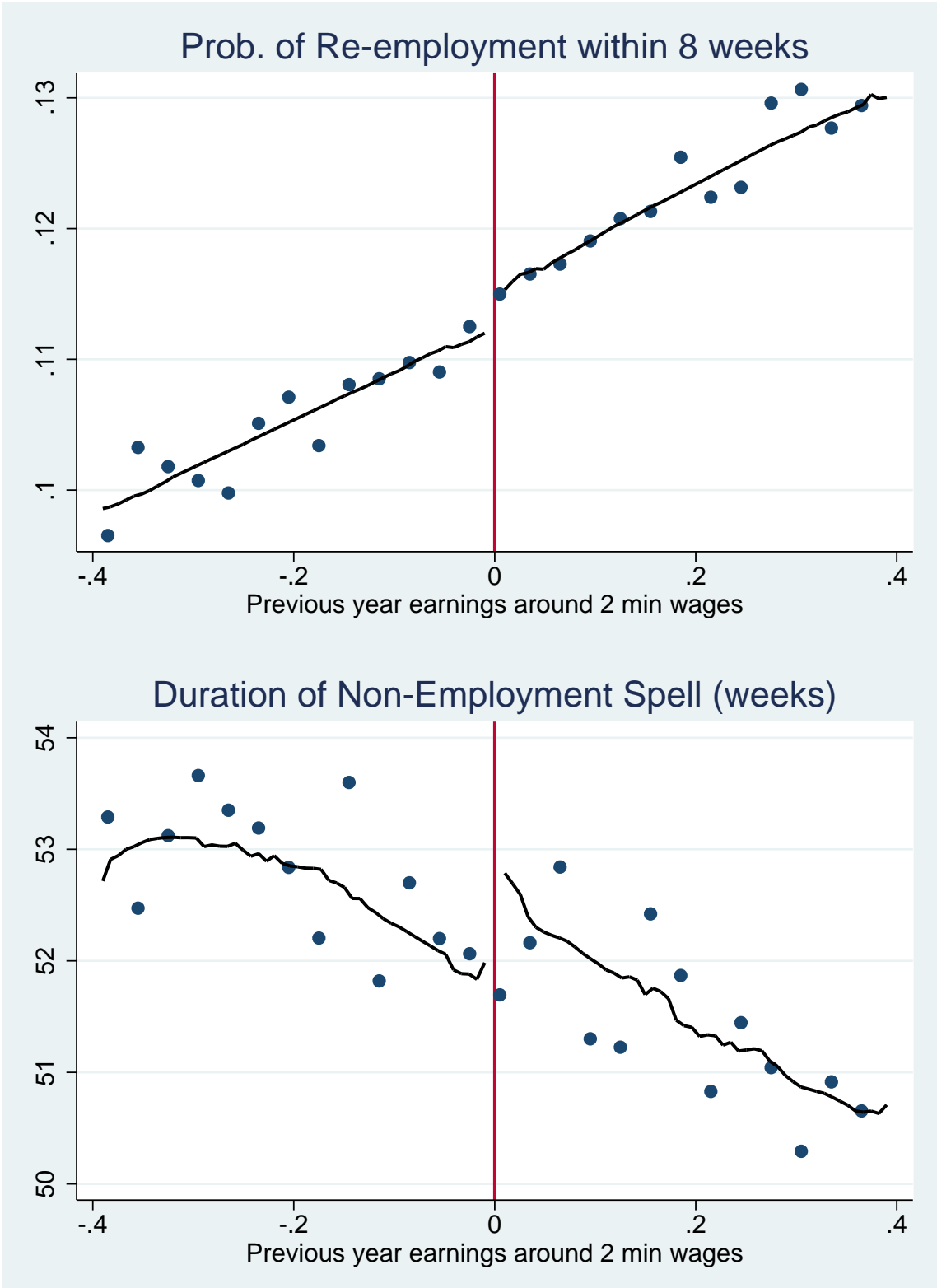

The graph displays how unemployment outcomes evolve around the threshold. At each side of the threshold, the conditional expectation function is approximated by a epanechnikov smoothed local linear polynomial with rectangular kernel. $s_{0}$ defines the probability of re-employment within 8 weeks. 
Figure 7: Unemployment Outcomes around 2 m.w. Threshold - Tenure $60-\infty$ months

Outcome Variables

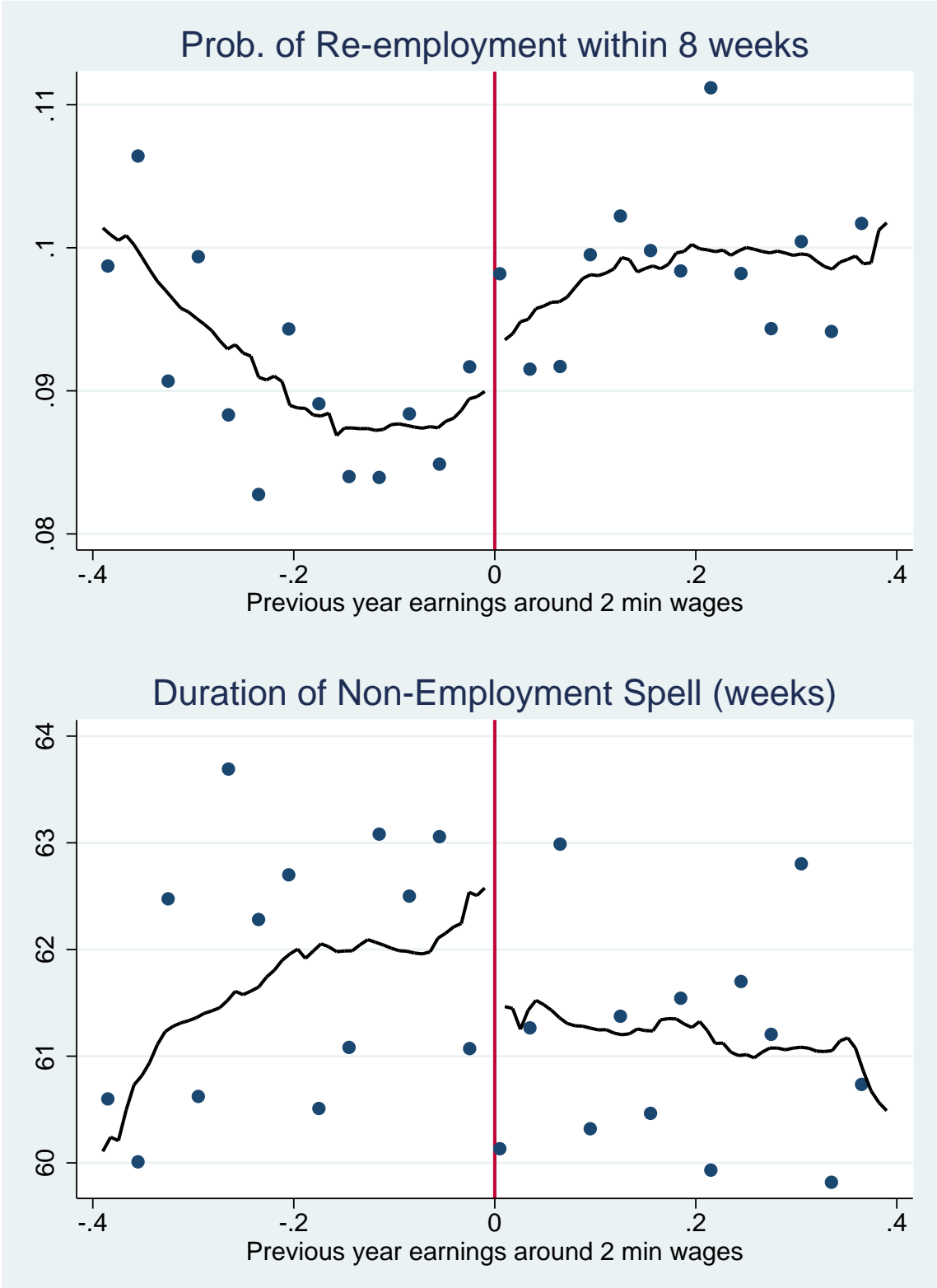

The graph displays how unemployment outcomes evolve around the threshold. At each side of the threshold, the conditional expectation function is approximated by a epanechnikov smoothed local linear polynomial with rectangular kernel. $s_{0}$ defines the probability of re-employment within 8 weeks. 
Figure 8: Unemployment Outcomes around 22-/24+ Tenure Threshold

\section{Outcome Variables}

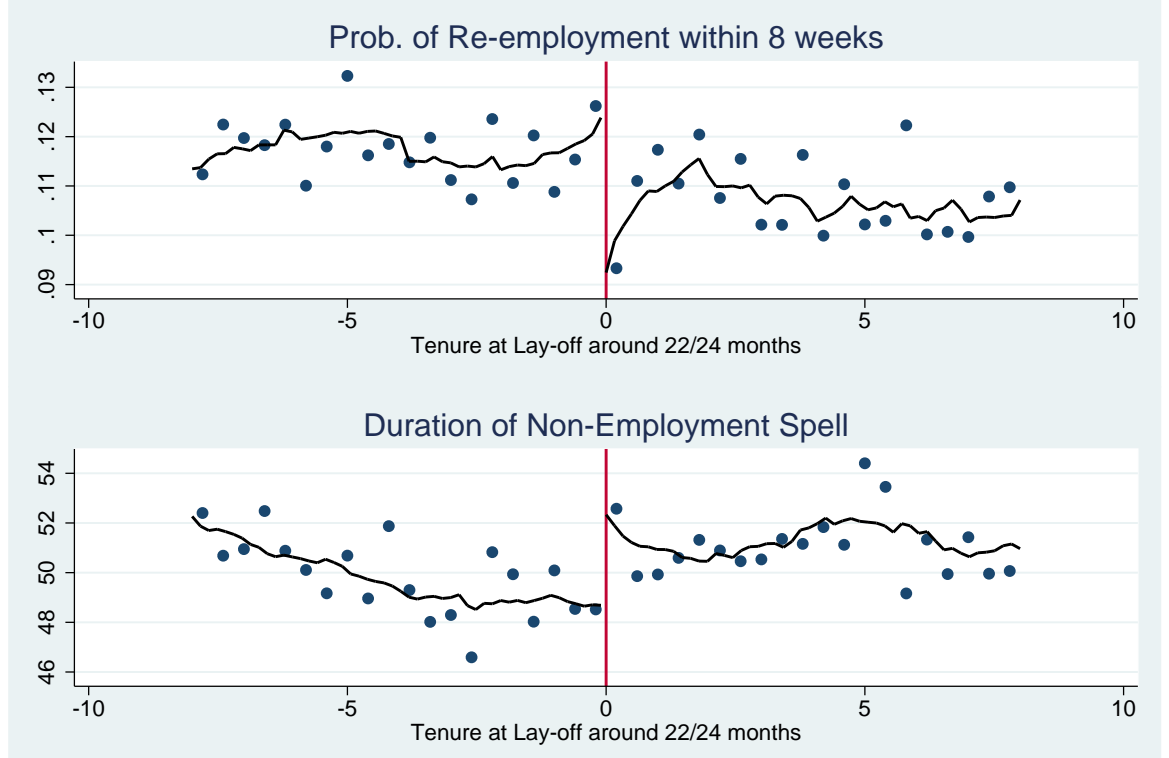

The graph displays how unemployment outcomes evolve around the threshold. At each side of the threshold, the conditional expectation function is approximated by a epanechnikov smoothed local linear polynomial with rectangular kernel. $s_{0}$ defines the probability of re-employment within 8 weeks. Unemployment duration is expressed in weeks. 
Figure 9: Covariates A around 22-/24+ Tenure Threshold

Continuity of Covariates A
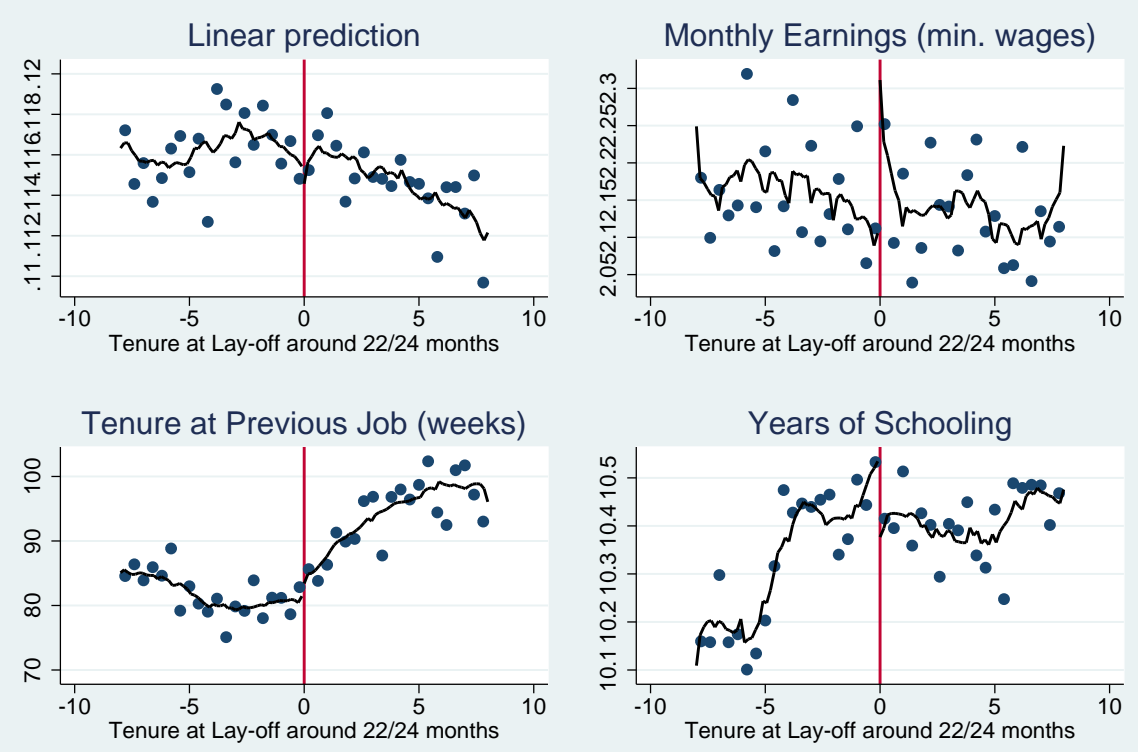

The graph displays how pre-determined covariates evolve around the threshold. At each side of the threshold, the conditional expectation function is approximated by a epanechnikov smoothed local linear polynomial with rectangular kernel.

Figure 10: Covariates B around 22-/24+ Tenure Threshold

\section{Continuity of Covariates B}
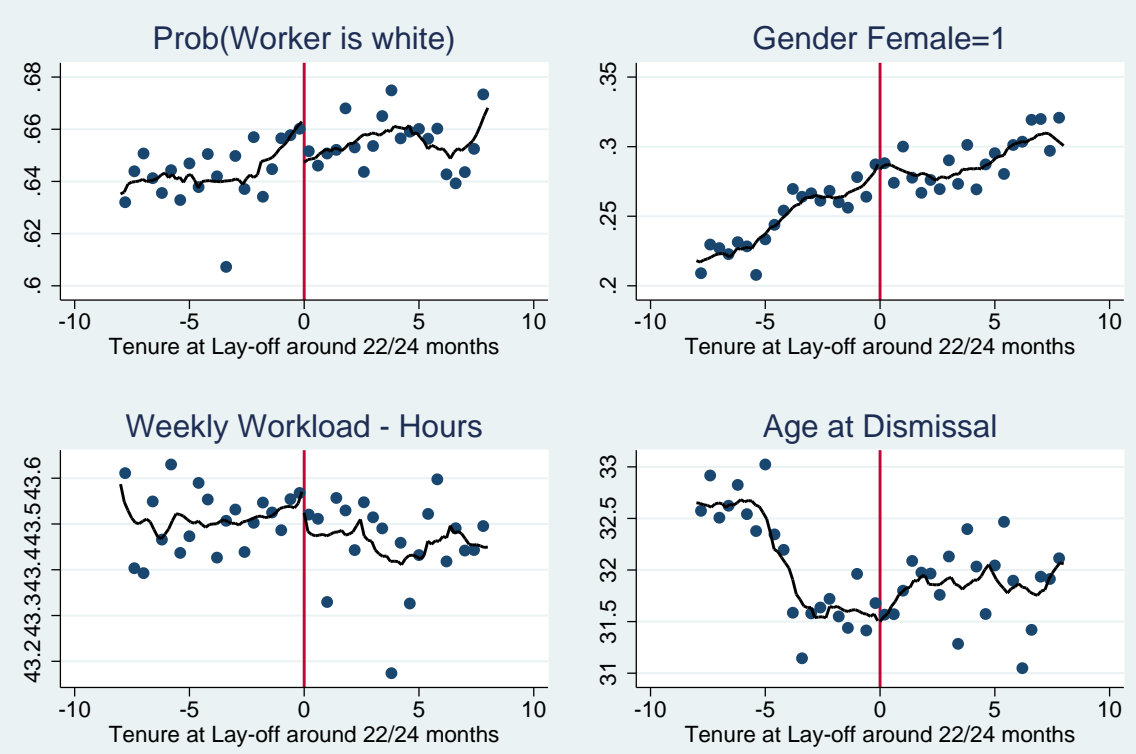

The graph displays how pre-determined covariates evolve around the threshold. At each side of the threshold, the conditional expectation function is approximated by a epanechnikov smoothed local linear polynomial with rectangular kernel. 


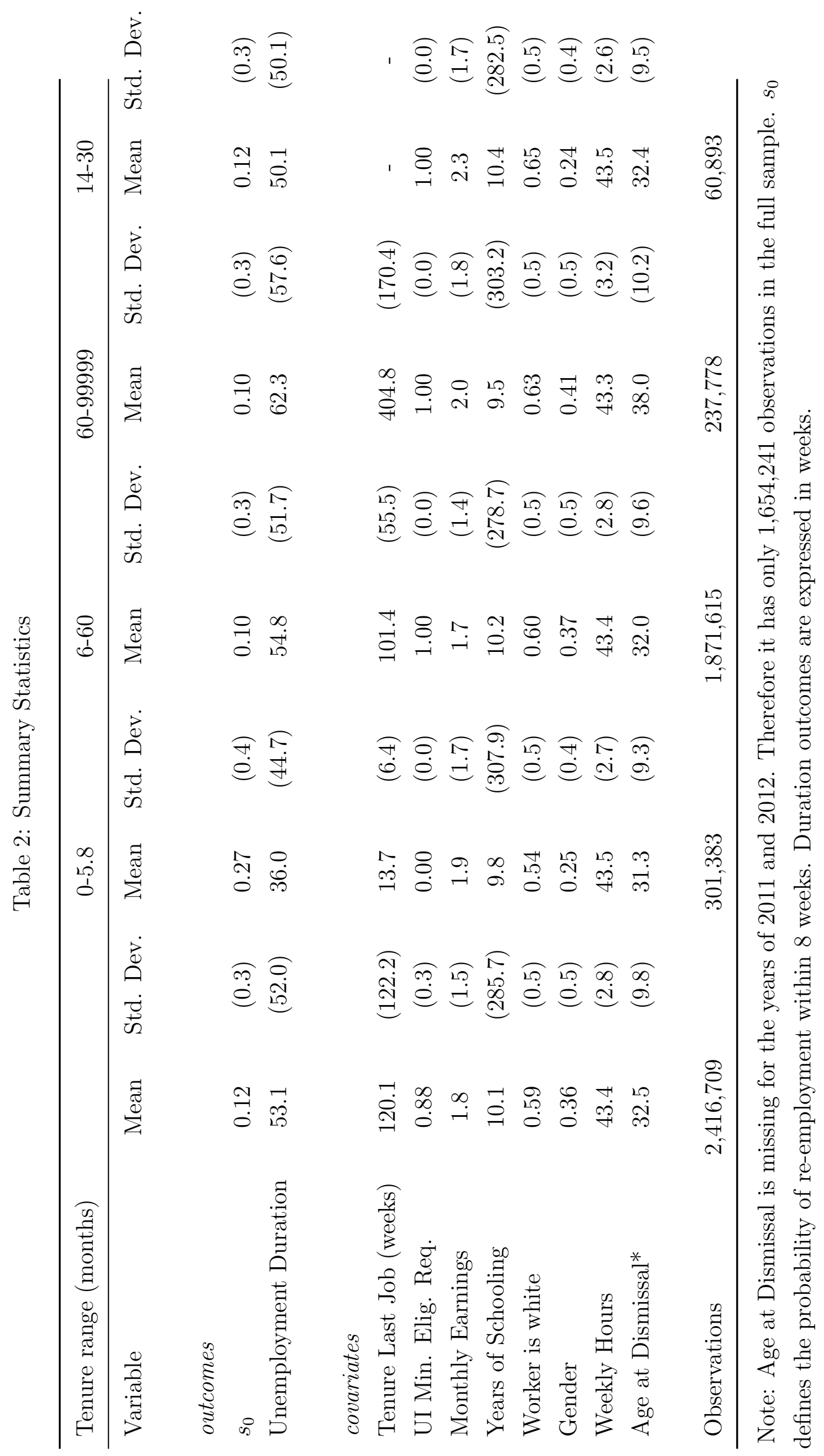


Table 3: RDD - Two Minimum Wages Threshold - Whole Sample

\begin{tabular}{|c|c|c|c|c|c|}
\hline & Discontinuity & s.e. & Discontinuity & s.e. & IK Bandwidth \\
\hline \multicolumn{6}{|l|}{ Outcomes } \\
\hline$s_{0}$ & $0.005^{* * *}$ & $(.002)$ & $0.005^{* * *}$ & $(0.002)$ & 0.36 \\
\hline Unemployment Duration & $0.478^{*}$ & $(.289)$ & 0.029 & $(0.274)$ & 0.29 \\
\hline \multicolumn{6}{|l|}{ Covariates } \\
\hline Predicted $s_{0}$ & -0.0002 & $(.0004)$ & & & 0.35 \\
\hline Predicted Unempl. Dur. & $0.599^{* * *}$ & $(.129)$ & & & 0.25 \\
\hline Tenure Last Job & $1.979^{* * *}$ & $(.57)$ & & & 0.61 \\
\hline UI Min. Elig. Req. & -0.0019 & $(.0017)$ & & & 0.40 \\
\hline Monthly Earnings & 0.002 & $(.008)$ & & & 0.38 \\
\hline Tenure Previous Job & -0.784 & $(.613)$ & & & 0.61 \\
\hline Years of Schooling & $-0.063^{* * *}$ & $(.018)$ & & & 0.25 \\
\hline Worker is white & -0.003 & $(.003)$ & & & 0.31 \\
\hline Gender & $-0.004^{* *}$ & $(.002)$ & & & 0.44 \\
\hline Weekly Hours & -0.011 & $(.016)$ & & & 0.35 \\
\hline Age at Dismissal & $0.246^{* * *}$ & $(.071)$ & & & 0.26 \\
\hline Controls & $\mathrm{N}$ & & $\mathrm{Y}$ & & \\
\hline
\end{tabular}

Note: The table displays discontinuities' estimates for each variable on the right side of the threshold, where workers are not eligible to the bonus due to the earnings criterion. All specifications use linear splines, bandwidth is selected according to IK selector and standard errors are displayed in parentheses. $s_{0}$ defines the probability of re-employment within 8 weeks. Duration outcomes are expressed in weeks. Predicted $s_{0}$ and Unemployment Duration are obtained by regressing each variable on a rich set of pre-determined covariates: quintile of average earnings in the previous year, decile of age at hiring and dismissal, employment duration at the start of the year, and dummies for each month of tenure in the last and previous job, industry of last and previous employer, dismissal cause at previous job, race, gender, weekly hours of work, year, calendar month of dismissal and federal state (27). 
Table 4: RDD - Two Minimum Wages Threshold - By Tenure Groups

\begin{tabular}{|c|c|c|c|c|c|c|}
\hline Tenure Range (months) & $0-5.8$ & & $6.0-60$ & & $60+$ & \\
\hline & Discontinuity & s.e. & Discontinuity & s.e. & Discontinuity & s.e. \\
\hline \multicolumn{7}{|l|}{ Outcomes } \\
\hline$s_{0}$ & $0.013^{* *}$ & $(.006)$ & $0.0037^{*}$ & $(0.002)$ & 0.006 & $(0.006)$ \\
\hline Unemployment Duration & $-1.629^{* * *}$ & $(.592)$ & $0.814^{* *}$ & $(0.363)$ & -0.878 & $(0.877)$ \\
\hline Controls & $\mathrm{N}$ & & $\mathrm{N}$ & & $\mathrm{N}$ & \\
\hline$s_{0}$ & $0.013^{* *}$ & $(.006)$ & $0.0034^{*}$ & $(0.002)$ & 0.005 & $(0.006)$ \\
\hline Unemployment Duration & $-1.924^{* * *}$ & $(.572)$ & 0.334 & $(0.347)$ & -0.212 & $(0.798)$ \\
\hline Controls & $\mathrm{Y}$ & & $\mathrm{Y}$ & & $\mathrm{Y}$ & \\
\hline \multicolumn{7}{|l|}{ Covariates } \\
\hline Predicted $s_{0}$ & $-0.002^{* *}$ & $(.0009)$ & $-0.001^{* * *}$ & $(0.000)$ & $0.002^{* * *}$ & $(0.001)$ \\
\hline Predicted Unempl. Dur. & $0.395^{*}$ & $(.235)$ & $0.718^{* * *}$ & $(0.138)$ & -0.499 & $(0.366)$ \\
\hline Tenure Last Job & -0.011 & $(.082)$ & 0.474 & $(0.389)$ & 0.328 & $(2.133)$ \\
\hline Monthly Earnings & -0.036 & $(.023)$ & 0.004 & $(0.009)$ & 0.03 & $(0.025)$ \\
\hline Tenure Previous Job & 1.12 & $(1.155)$ & -0.657 & $(0.811)$ & -1.882 & $(2.969)$ \\
\hline Years of Schooling & -0.064 & $(.046)$ & $-0.052^{* * *}$ & $(0.018)$ & -0.026 & $(0.036)$ \\
\hline Worker is white & -0.003 & $(.006)$ & 0 & $(0.003)$ & -0.008 & $(0.008)$ \\
\hline Gender & -0.006 & $(.006)$ & -0.002 & $(0.003)$ & $-0.014^{* *}$ & $(0.007)$ \\
\hline Weekly Hours & 0.028 & $(.029)$ & -0.024 & $(0.019)$ & -0.053 & $(0.045)$ \\
\hline Age at Dismissal & 0.091 & $(.158)$ & $0.25 * * *$ & $(0.079)$ & 0.239 & $(0.188)$ \\
\hline
\end{tabular}

Note: The table displays discontinuities' estimates for each variable on the right side of the threshold, where workers are not eligible to the bonus due to the earnings criterion. All specifications use linear splines, bandwidth is selected according to IK selector and standard errors are displayed in parentheses. $s_{0}$ defines the probability of re-employment within 8 weeks. Duration outcomes are expressed in weeks. Predicted $s_{0}$ and Unemployment Duration are obtained by regressing each variable on a rich set of pre-determined covariates: quintile of average earnings in the previous year, decile of age at hiring and dismissal, employment duration at the start of the year, and dummies for each month of tenure in the last and previous job, industry of last and previous employer, dismissal cause at previous job, race, gender, weekly hours of work, year, calendar month of dismissal and federal state (27). 
Table 5: RDD - Two Minimum Wages Threshold - Only Eligible Workers

\begin{tabular}{lccccc}
\hline & Discontinuity & s.e. & Discontinuity & s.e. & IK Bandwidth \\
\hline Outcomes & & & & & \\
$s_{0}$ & 0.0043 & $(.0044)$ & 0.0064 & $(0.0043)$ & 0.27 \\
Unemployment Duration & -0.074 & $(.339)$ & -0.402 & $(0.320)$ & 0.26 \\
& & & & & \\
Covariates & & & & & 0.50 \\
Predicted $s_{0}$ & $-0.0042^{* * *}$ & $(.0009)$ & & & 0.43 \\
Predicted Unempl. Dur. & $0.685^{* * *}$ & $(.148)$ & & & 0.50 \\
Tenure Last Job & $5.251^{* * *}$ & $(1.166)$ & & 0.62 \\
UI Min. Elig. Req. & -0.0002 & $(.0008)$ & & & 0.41 \\
Monthly Earnings & -0.005 & $(.011)$ & & 0.49 \\
Tenure Previous Job & 0.173 & $(1.244)$ & & 0.42 \\
Years of Schooling & -0.001 & $(.025)$ & & 0.22 \\
Worker is white & 0.002 & $(.006)$ & & 0.32 \\
Gender & 0.005 & $(.004)$ & & 0.47 \\
Weekly Hours & -0.009 & $(.022)$ & & 0.43 \\
Age at Dismissal & 0.153 & $(.141)$ & & \\
Controls & & & & \\
\hline
\end{tabular}

Note: This sample is restricted only to workers who surely attend the five years eligibility criterion. The table displays discontinuities' estimates for each variable on the right side of the threshold, where workers are not eligible to the bonus due to the earnings criterion. All specifications use linear splines, bandwidth is selected according to IK selector and standard errors are displayed in parentheses. $s_{0}$ defines the probability of re-employment within 12 weeks. Duration outcomes are expressed in weeks. Predicted $s_{0}$ and Unemployment Duration are obtained by regressing each variable on a rich set of pre-determined covariates: quintile of average earnings in the previous year, decile of age at hiring and dismissal, employment duration at the start of the year, and dummies for each month of tenure in the last and previous job, industry of last and previous employer, dismissal cause at previous job, race, gender, weekly hours of work, year, calendar month of dismissal and federal state (27). 
Table 6: Effect of Bonus Provision - Only Eligible Workers by Tenure Group

\begin{tabular}{|c|c|c|c|c|c|c|}
\hline Tenure Range (months) & $0-5.8$ & & $6.0-60$ & & $60+$ & \\
\hline & Discontinuity & s.e. & Discontinuity & s.e. & Discontinuity & s.e. \\
\hline \multicolumn{7}{|l|}{ Outcomes } \\
\hline$s_{0}$ & 0.013 & $(.0112)$ & 0.0059 & $(0.0052)$ & 0.005 & $(0.0063)$ \\
\hline Unemployment Duration & -0.1 & $(.669)$ & 0.208 & $(0.375)$ & -0.87 & $(0.863)$ \\
\hline Controls & $\mathrm{N}$ & & $\mathrm{N}$ & & $\mathrm{N}$ & \\
\hline$s_{0}$ & 0.016 & $(.0112)$ & 0.0067 & $(0.0051)$ & 0.006 & $(0.0061)$ \\
\hline Unemployment Duration & -0.473 & $(.651)$ & -0.099 & $(0.362)$ & -0.582 & $(0.788)$ \\
\hline Controls & $\mathrm{Y}$ & & Y & & $\mathrm{Y}$ & \\
\hline \multicolumn{7}{|l|}{ Covariates } \\
\hline Predicted $s_{0}$ & $-0.007^{* * *}$ & $(.0024)$ & $-0.003^{* * *}$ & $(0.001)$ & -0.001 & $(0.002)$ \\
\hline Predicted Unempl. Dur. & $0.966^{* * *}$ & $(.369)$ & $0.71^{* * *}$ & $(0.166)$ & 0.026 & $(0.361)$ \\
\hline Tenure Last Job & 0.03 & $(0.166)$ & $1.659^{* * *}$ & $(0.629)$ & -1.086 & $(3.439)$ \\
\hline Monthly Earnings & 0.026 & $(.038)$ & 0.002 & $(0.013)$ & $-0.04^{*}$ & $(0.024)$ \\
\hline Tenure Previous Job & 3.408 & $(2.329)$ & -1.023 & $(1.243)$ & -2.904 & $(4.619)$ \\
\hline Years of Schooling & 0.043 & $(.073)$ & 0.03 & $(0.033)$ & -0.009 & $(0.067)$ \\
\hline Worker is white & -0.007 & $(0.012)$ & 0 & $(0.005)$ & 0 & $(0.011)$ \\
\hline Gender & 0.012 & $(.01)$ & 0.005 & $(0.005)$ & -0.011 & $(0.010)$ \\
\hline Weekly Hours & 0.034 & $(.05)$ & -0.039 & $(0.026)$ & 0.059 & $(0.062)$ \\
\hline Age at Dismissal & -0.152 & $(.371)$ & 0.156 & $(0.162)$ & 0.079 & $(0.323)$ \\
\hline
\end{tabular}

Note: This sample is restricted only to workers who surely attend the five years eligibility criterion. The table displays discontinuities' estimates for each variable on the right side of the threshold, where workers are not eligible to the bonus due to the earnings criterion. All specifications use linear splines, bandwidth is selected according to IK selector and standard errors are displayed in parentheses. $s_{0}$ defines the probability of re-employment within 12 weeks. Duration outcomes are expressed in weeks. Predicted $s_{0}$ and Unemployment Duration are obtained by regressing each variable on a rich set of pre-determined covariates: quintile of average earnings in the previous year, decile of age at hiring and dismissal, employment duration at the start of the year, and dummies for each month of tenure in the last and previous job, industry of last and previous employer, dismissal cause at previous job, race, gender, weekly hours of work, year, calendar month of dismissal and federal state (27). 
Table 7: Effect of Extra Month of Unemployment Benefits - Displaced workers with around $22^{-} / 24^{+}$ months of tenure

\begin{tabular}{|c|c|c|c|c|c|}
\hline & Discontinuity & s.e. & Discontinuity & s.e. & IK Bandwidth \\
\hline \multicolumn{6}{|l|}{ Outcomes } \\
\hline$s_{0}$ & $-0.018^{*}$ & $(.011)$ & $-0.019^{*}$ & $(0.010)$ & 2.35 \\
\hline Unemployment Duration & $2.188^{* *}$ & $(.955)$ & 1.158 & $(0.927)$ & 6.77 \\
\hline \multicolumn{6}{|l|}{ Covariates } \\
\hline Predicted $s_{0}$ & 0.0017 & $(.002)$ & & & 2.31 \\
\hline Predicted Unempl. Dur. & -0.6035 & $(.673)$ & & & 2.15 \\
\hline Monthly Earnings & $0.1308^{* * *}$ & $(.05)$ & & & 2.19 \\
\hline Tenure Previous Job & 4.2367 & $(3.9931)$ & & & 3.81 \\
\hline Years of Schooling & -0.1504 & $(.0942)$ & & & 2.07 \\
\hline Worker is white & -0.0201 & $(.0176)$ & & & 2.28 \\
\hline Gender & 0.0187 & $(.0137)$ & & & 2.61 \\
\hline Weekly Hours & -0.0701 & $(.0677)$ & & & 3.82 \\
\hline Age at Dismissal & $0.5978^{*}$ & $(.3261)$ & & & 3.20 \\
\hline Controls & $\mathrm{N}$ & & $\mathrm{Y}$ & & \\
\hline
\end{tabular}

Note: The table displays discontinuities' estimates for each variable on the right side of the threshold for an extra month of potential UI duration. On the left side of the threshold are workers with less than 22 months of tenure, while on the right side are workers with more than 24 months of tenure; workers in between are not included due to reasons discussed in the text. All specifications use linear splines, bandwidth is selected according to IK selector and standard errors are displayed in parentheses. $s_{0}$ defines the probability of re-employment within 8 weeks. Duration outcomes are expressed in weeks. Predicted $s_{0}$ and Unemployment Duration are obtained by regressing each variable on a rich set of pre-determined covariates: quantile of average earnings in the previous year, decile of age at hiring and dismissal, and dummies for industry of last employer, race, gender, weekly hours of work, year, calendar month of dismissal, federal state (27) and eligibility for yearly bonus. 
Table 8: Liquidity to Moral Hazard Estimates

\begin{tabular}{lcc}
\hline Empirics I - Liquidity Effect & & \\
\hline specification & Tenure 6 - 60 & Whole Sample \\
$\Delta s_{0}$ & -0.0068 & -0.0065 \\
$\Delta A_{0}$ & 592.11 & 592.42 \\
$\frac{\partial s_{0}}{\partial A_{0}} \times 10^{3}$ & -0.0115 & -0.0109 \\
\hline Empirics II - Potential Duration Effect & & \\
\hline$s_{0}$ & & \\
$\Delta b_{t}$ & -0.0190 & -0.0190 \\
$\frac{\partial s_{0}}{\partial b_{t}} \times 10^{3}$ & 830.9 & 830.9 \\
\hline Moral Hazard Estimate & -0.0229 & -0.0229 \\
\hline$S_{t}$ & & \\
$\frac{\partial s_{0}}{\partial w_{0}} \times 10^{3}$ & & \\
\hline Liquidity-to-Moral Hazard Estimate & 0.857 & 0.857 \\
\hline $\bar{S}_{1}^{B}$ & 0.0133 & 0.0140 \\
Liquidity-to-Moral Hazard Ratio $\rho$ & & \\
\hline
\end{tabular}

Note: Currency values are expressed in reais in 2012 prices. 


\section{A Figures}

Figure A1: Covariates A around 2 m.w. Threshold - Tenure 0-5.8 months

\section{Continuity of Covariates A}
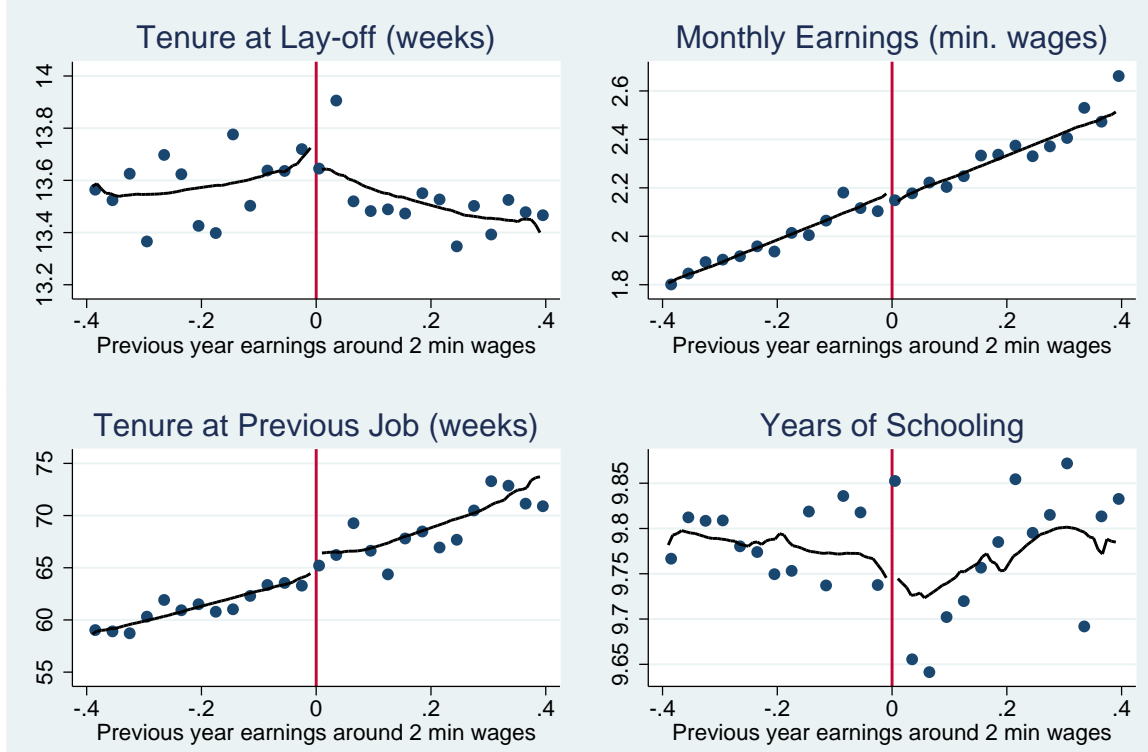

The graph displays how pre-determined covariates evolve around the threshold. At each side of the threshold, the conditional expectation function is approximated by a epanechnikov smoothed local linear polynomial with rectangular kernel. 
Figure A2: Covariates B around 2 m.w. Threshold - Tenure 0-5.8 months

\section{Continuity of Covariates B}
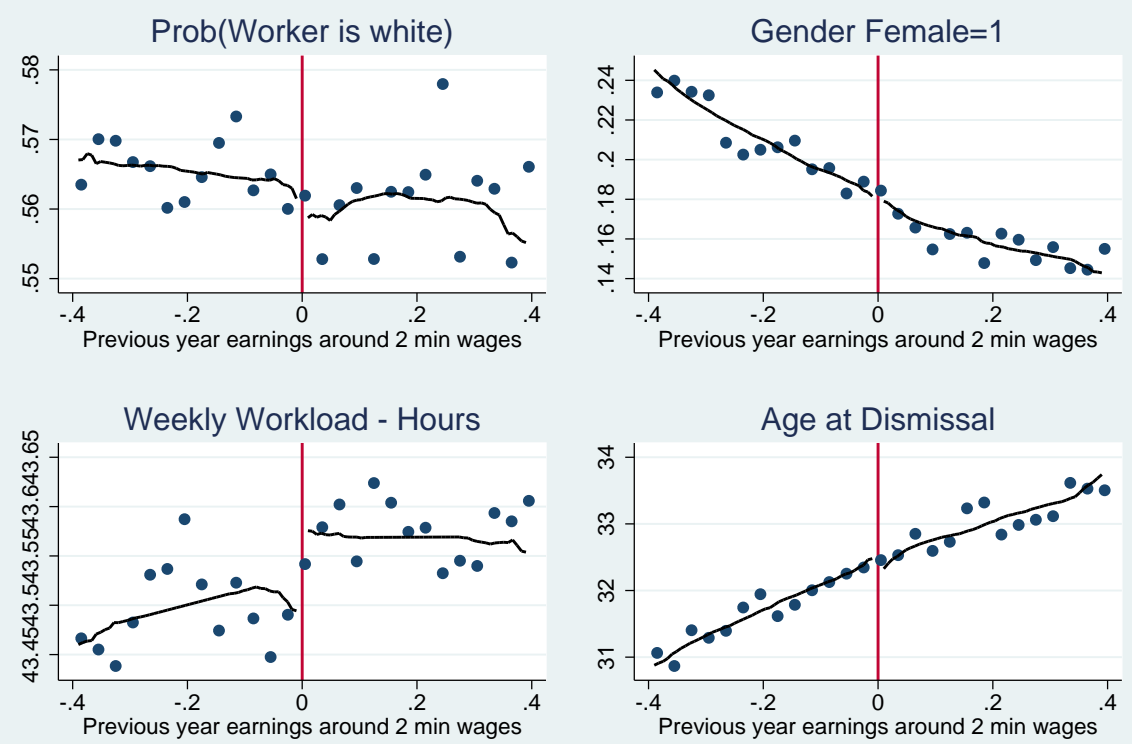

The graph displays how pre-determined covariates evolve around the threshold. At each side of the threshold, the conditional expectation function is approximated by a epanechnikov smoothed local linear polynomial with rectangular kernel.

Figure A3: Covariates A around 2 m.w. Threshold - Tenure 6-60 months

Continuity of Covariates A
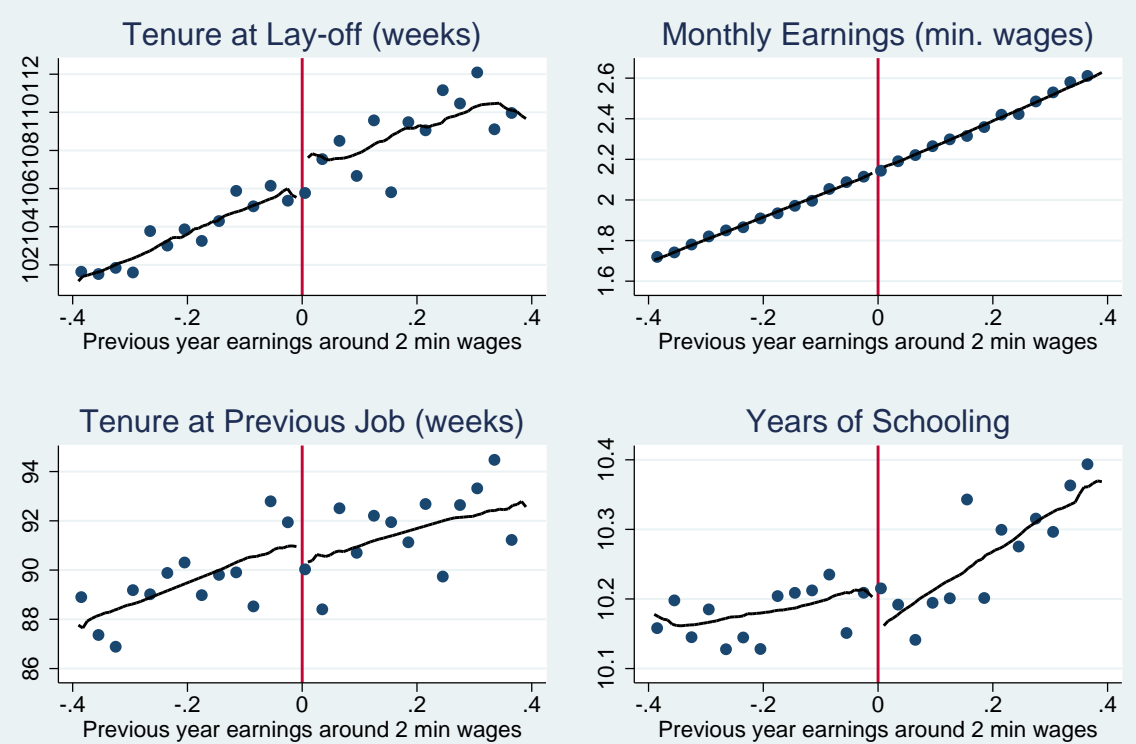

The graph displays how pre-determined covariates evolve around the threshold. At each side of the threshold, the conditional expectation function is approximated by a epanechnikov smoothed local linear polynomial with rectangular kernel. 
Figure A4: Covariates B around 2 m.w. Threshold - Tenure 6-60 months

\section{Continuity of Covariates B}
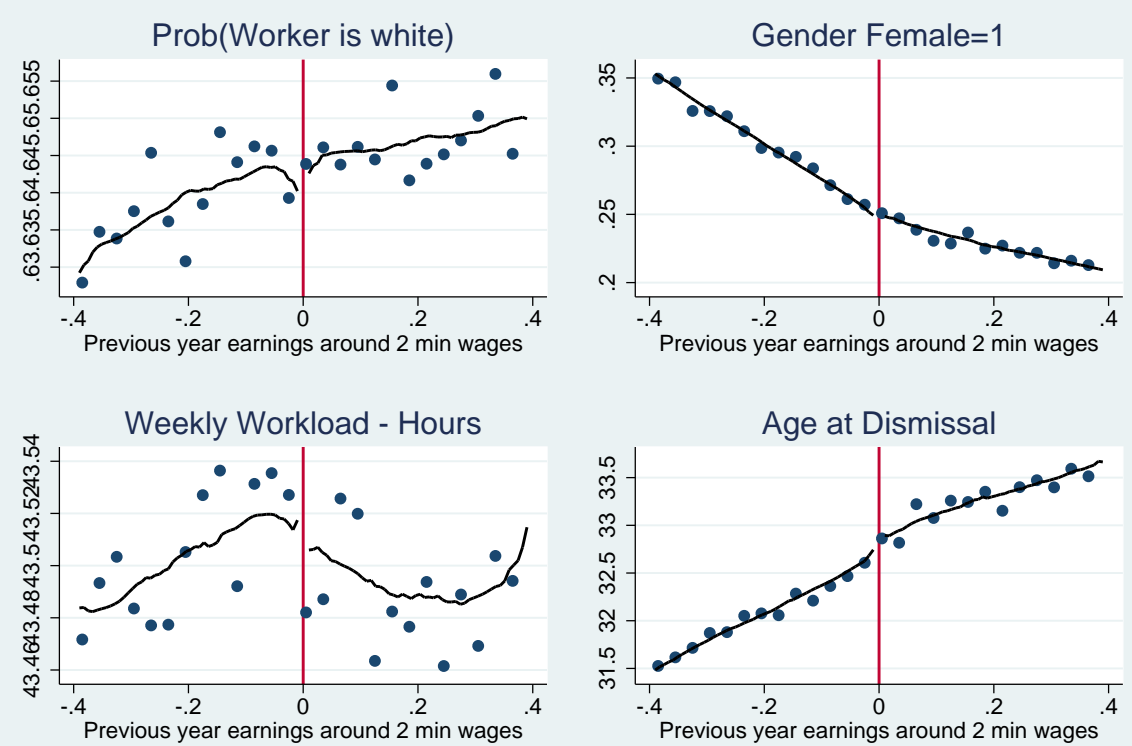

The graph displays how pre-determined covariates evolve around the threshold. At each side of the threshold, the conditional expectation function is approximated by a epanechnikov smoothed local linear polynomial with rectangular kernel.

Figure A5: Covariates A around 2 m.w. Threshold - Tenure $60-\infty$ months

Continuity of Covariates A
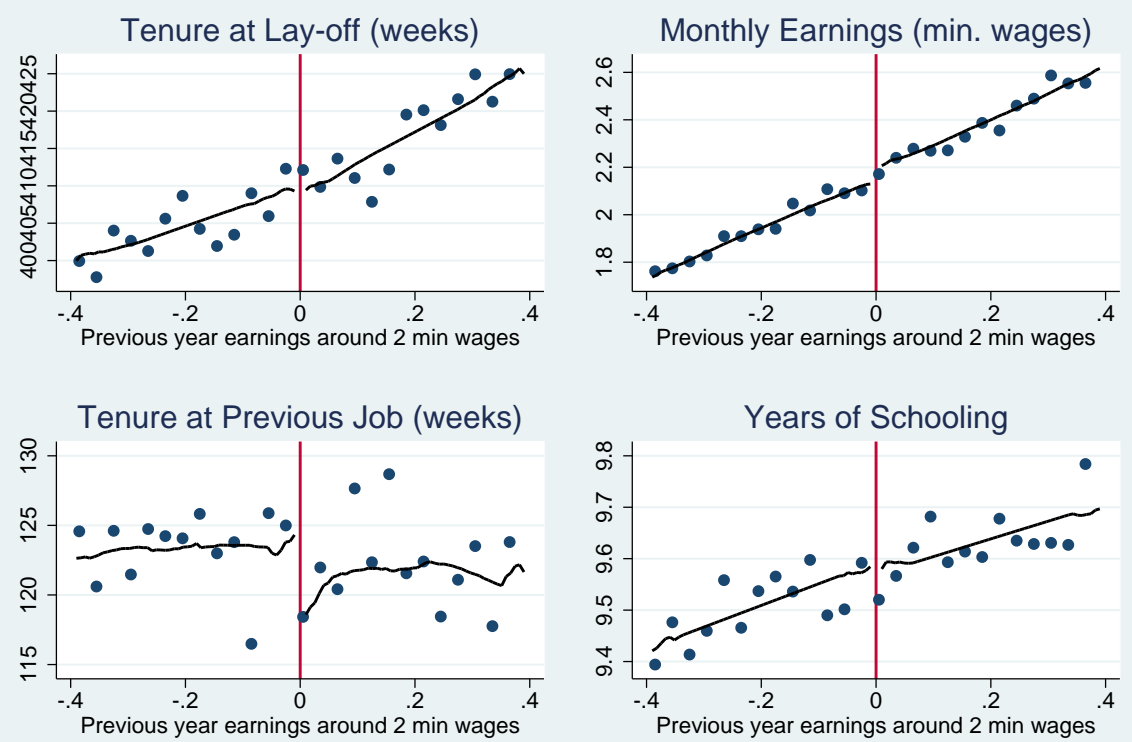

The graph displays how pre-determined covariates evolve around the threshold. At each side of the threshold, the conditional expectation function is approximated by a epanechnikov smoothed local linear polynomial with rectangular kernel. 
Figure A6: Covariates B around 2 m.w. Threshold - Tenure $60-\infty$ months

\section{Continuity of Covariates B}
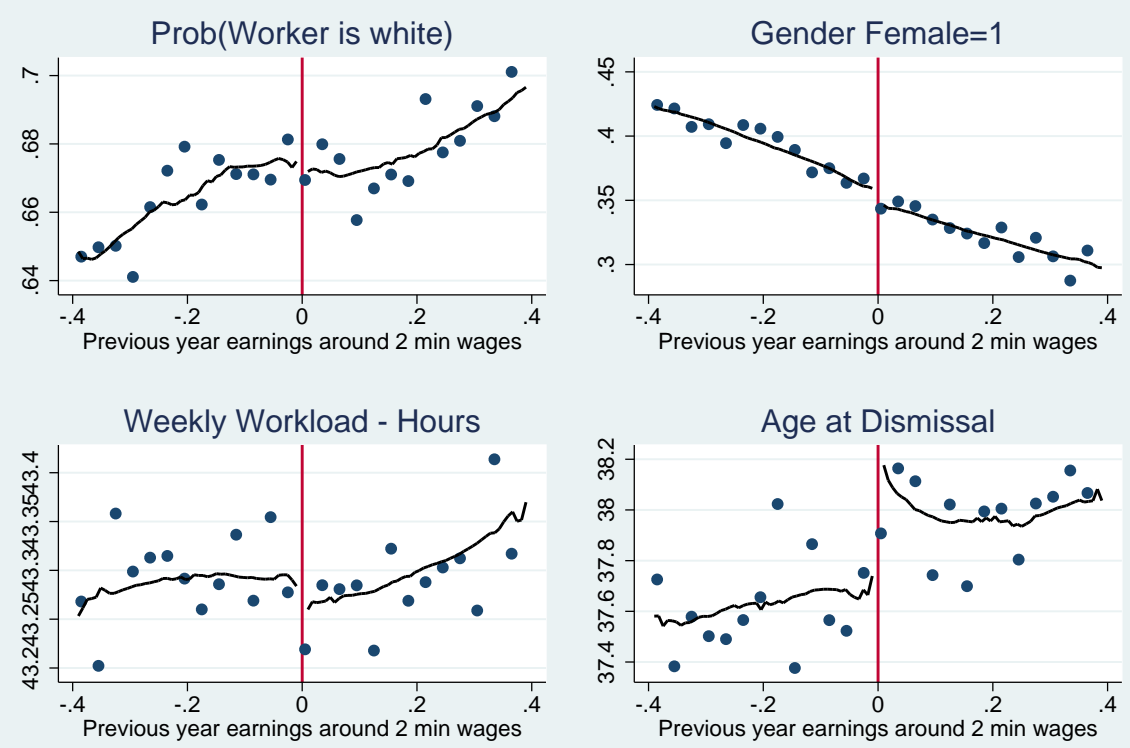

The graph displays how pre-determined covariates evolve around the threshold. At each side of the threshold, the conditional expectation function is approximated by a epanechnikov smoothed local linear polynomial with rectangular kernel. 


\section{B Tables}

Table B1: Effect of Bonus Provision - Only Eligible Workers By Tenure Group - Local Quadratic Regressions

\begin{tabular}{|c|c|c|c|c|c|c|}
\hline Tenure Range (months) & $0-5.8$ & & $6.0-60$ & & $60+$ & \\
\hline & Discontinuity & s.e. & Discontinuity & s.e. & Discontinuity & s.e. \\
\hline \multicolumn{7}{|l|}{ Outcomes } \\
\hline$s_{0}$ & $0.019^{*}$ & $(.012)$ & 0.0083 & $(0.0058)$ & 0.003 & $(0.010)$ \\
\hline Unemployment Duration & 0.546 & $(.89)$ & -0.404 & $(0.450)$ & -0.877 & $(0.972)$ \\
\hline Controls & $\mathrm{N}$ & & $\mathrm{N}$ & & $\mathrm{N}$ & \\
\hline$s_{0}$ & $0.024^{* *}$ & $(.012)$ & 0.0087 & $(0.0056)$ & 0.004 & $(0.010)$ \\
\hline Unemployment Duration & 0.167 & $(.87)$ & $-0.742^{*}$ & $(0.437)$ & -0.798 & $(0.884)$ \\
\hline Controls & $\mathrm{Y}$ & & $\mathrm{Y}$ & & $\mathrm{Y}$ & \\
\hline \multicolumn{7}{|l|}{ Covariates } \\
\hline Predicted $s_{0}$ & $-0.006^{*}$ & $(.0037)$ & $-0.003^{* * *}$ & $(0.001)$ & 0 & $(0.003)$ \\
\hline Predicted Unempl. Dur. & $1.297^{* *}$ & $(.581)$ & -0.249 & $(0.276)$ & -0.305 & $(0.557)$ \\
\hline Tenure Last Job & 0.045 & $(0.208)$ & $3.038^{* * *}$ & $(0.966)$ & -3.448 & $(5.183)$ \\
\hline Monthly Earnings & 0.028 & $(.052)$ & 0.009 & $(0.018)$ & -0.041 & $(0.032)$ \\
\hline Tenure Previous Job & 2.738 & $(3.162)$ & -1.86 & $(1.770)$ & -3.286 & $(6.328)$ \\
\hline Years of Schooling & 7.363 & $(10.665)$ & 4.703 & $(4.177)$ & 1.148 & $(8.518)$ \\
\hline Worker is white & -0.005 & $(0.014)$ & 0.004 & $(0.007)$ & -0.001 & $(0.013)$ \\
\hline Gender & 0.01 & $(.012)$ & 0.005 & $(0.007)$ & 0.001 & $(0.013)$ \\
\hline Weekly Hours & $0.18^{* *}$ & $(.081)$ & -0.047 & $(0.032)$ & 0.071 & $(0.079)$ \\
\hline Age at Dismissal & -0.279 & $(.486)$ & -0.218 & $(0.266)$ & 0.216 & $(0.412)$ \\
\hline
\end{tabular}

Note: This sample is restricted only to workers who surely attend the five years eligibility criterion. The table displays discontinuities' estimates for each variable on the right side of the threshold, where workers are not eligible to the bonus due to the earnings criterion. All specifications use linear splines, bandwidth is selected according to IK selector and standard errors are displayed in parentheses. $s_{0}$ defines the probability of re-employment within 12 weeks. Duration outcomes are expressed in weeks. Predicted $s_{0}$ and Unemployment Duration are obtained by regressing each variable on a rich set of pre-determined covariates: quintile of average earnings in the previous year, decile of age at hiring and dismissal, employment duration at the start of the year, and dummies for each month of tenure in the last and previous job, industry of last and previous employer, dismissal cause at previous job, race, gender, weekly hours of work, year, calendar month of dismissal and federal state (27). 
Table B2: Placebo Thresholds on Tenure Discontinuity with 2 months gap

\begin{tabular}{lccccc}
\hline Dep. Var.: $s_{0}$ & Discontinuity & s.e. & Discontinuity & s.e. & Bandwidth \\
\hline \multicolumn{7}{c}{ Placebo A: $16^{-} / 18^{+}$Threshold } \\
linear specification & \multicolumn{7}{c}{. } \\
0.5 IK Bandwidth & -0.027 & $(.029)$ & -0.027 & $(0.028)$ & 0.69 \\
IK Bandwidth & 0.001 & $(.02)$ & 0 & $(0.020)$ & 1.38 \\
1.5 IK Bandwidth & -0.021 & $(.016)$ & -0.018 & $(0.015)$ & 2.07 \\
& & & & & \\
quadratic specification & & & & & \\
0.5 IK Bandwidth & -0.02 & $(.03)$ & -0.02 & $(0.030)$ & 1.37 \\
IK Bandwidth & -0.001 & $(.021)$ & 0 & $(0.021)$ & 2.74 \\
1.5 IK Bandwidth & -0.022 & $(.017)$ & -0.02 & $(0.017)$ & 4.10 \\
& & & & & \\
Controls & $\mathrm{N}$ & & $\mathrm{Y}$ & & \\
\hline
\end{tabular}

linear specification

$\begin{array}{lccccc}0.5 \text { IK Bandwidth } & -0.027 & (.023) & -0.025 & (0.023) & 0.83 \\ \text { IK Bandwidth } & -0.003 & (.016) & -0.001 & (0.016) & 1.66 \\ \text { 1.5 IK Bandwidth } & 0.007 & (.013) & 0.008 & (0.013) & 2.50\end{array}$

quadratic specification

$\begin{array}{llllll}\text { 0.5 IK Bandwidth } & -0.01 & (.037) & -0.01 & (0.037) & 0.93 \\ \text { IK Bandwidth } & -0.005 & (.023) & -0.002 & (0.024) & 1.86 \\ \text { 1.5 IK Bandwidth } & -0.006 & (.019) & -0.004 & (0.019) & 2.80\end{array}$

Controls N $\quad$ Y

Note: The table displays discontinuities' estimates on $s_{0}$ for two placebo thresholds at which there is no change in UI potential duration. On the left side of each threshold are workers with less than 16 and 30 months of tenure respectively, while on the right side are workers with more than 18 and 32 months of tenure respectively; workers in between are not included due to reasons discussed in the text. Bandwidth is selected according to IK selector and standard errors are displayed in parentheses. $s_{0}$ defines the probability of re-employment within 8 weeks. 


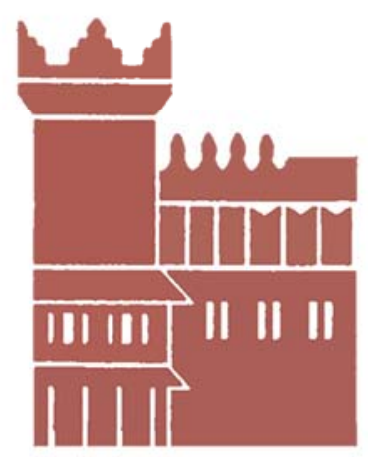

Alma Mater Studiorum - Università di Bologna DEPARTMENT OF ECONOMICS

Strada Maggiore 45

40125 Bologna - Italy

Tel. +39051 2092604

Fax +390512092664

http://www.dse.unibo.it 